\title{
The Contribution of Raised Intraneuronal Chloride to Epileptic Network Activity
}

\author{
Hannah Alfonsa, ${ }^{1}$ EEdward M. Merricks, ${ }^{1 *}$ Neela K. Codadu, ${ }^{1 *}$ Mark 0. Cunningham, ${ }^{1}$ Karl Deisseroth, ${ }^{2,3,4}$ \\ Claudia Racca, ${ }^{1}$ and ${ }^{\circledR}$ Andrew J. Trevelyan ${ }^{1}$ \\ ${ }^{1}$ Institute of Neuroscience, Medical School, Newcastle upon Tyne, NE2 4HH, United Kingdom, and Departments of ${ }^{2}$ Bioengineering and ${ }^{3}$ Psychiatry and \\ ${ }^{4}$ Howard Hughes Medical Institute, Stanford University, Stanford, California 94305
}

\begin{abstract}
Altered inhibitory function is an important facet of epileptic pathology. A key concept is that GABAergic activity can become excitatory if intraneuronal chloride rises. However, it has proved difficult to separate the role of raised chloride from other contributory factors in complex network phenomena, such as epileptic pathology. Therefore, we asked what patterns of activity are associated with chloride dysregulation by making novel use of Halorhodopsin to load clusters of mouse pyramidal cells artificially with $\mathrm{Cl}^{-}$. Brief $(1-10 \mathrm{~s})$ activation of Halorhodopsin caused substantial positive shifts in the GABAergic reversal potential that were proportional to the charge transfer during the illumination and in adult neocortical pyramidal neurons decayed with a time constant of $\tau=8.0 \pm 2.8 \mathrm{~s}$. At the network level, these positive shifts in $E_{\mathrm{GABA}}$ produced a transient rise in network excitability, with many distinctive features of epileptic foci, including high-frequency oscillations with evidence of out-of-phase firing (Ibarz et al., 2010). We show how such firing patterns can arise from quite small shifts in the mean intracellular $\mathrm{Cl}^{-}$level, within heterogeneous neuronal populations. Notably, however, chloride loading by itself did not trigger full ictal events, even with additional electrical stimulation to the underlying white matter. In contrast, when performed in combination with low, subepileptic levels of 4-aminopyridine, Halorhodopsin activation rapidly induced full ictal activity. These results suggest that chloride loading has at most an adjunctive role in ictogenesis. Our simulations also show how chloride loading can affect the jitter of action potential timing associated with imminent recruitment to an ictal event (Netoff and Schiff, 2002).
\end{abstract}

Key words: chloride; fast spiking interneuron; high frequency oscillations; neocortex; pyramidal neuron; seizure

\section{Introduction}

Inhibitory dysfunction has long been considered to be a major factor in triggering epileptic seizures (Miles and Wong, 1983; Sloviter, 1987; Traub and Miles, 1991; Cossart et al., 2005; Pinto et al., 2005; Huberfeld et al., 2007; Zsiros and Maccaferri, 2008; Kaila et al., 2014; Pallud et al., 2014). In recent years, particular attention has focused on how positive shifts in the GABAergic reversal potential, caused by raised intracellular $\mathrm{Cl}^{-}$levels in neurons, may contribute to this process. Recordings from human

\section{Received Oct. 4, 2014; revised March 17, 2015; accepted March 28, 2015.}

Author contributions: H.A. and A.J.T. designed research; H.A., N.K.C., C.R., and A.J.T. performed research; M.O.C. and K.D. contributed unpublished reagents/analytic tools; H.A., E.M.M., and A.J.T. analyzed data; H.A. and A.J.T. wrote the paper.

This work was supported by a Medical Research Council project grant (A.J.T. and C.R.) and a Wellcome Trust studentship (E.M.M.). K.D. is supported by the National Institute of Mental Health, the Simons Foundation Autism Research Initiative, the National Institute on Drug Abuse, the Defense Advanced Research Projects Agency, the Gatsby Charitable Foundation, and the Wiegers Family Fund. We thank Sasha Gartside and Richard McQuade for help and loan of equipment for stereotaxic injections, Trevor Booth at the Bio-Imaging Unit in Newcastle University, and Bob Lightowlers and Jeremy Lakey for support during the project. We thank Giles Hardingham and his group for teaching us how to prepare dissociated neuronal cultures. We thank Liset Menendez de la Prida, Ryley Parrish, and Cathy Schevon for commenting on this manuscript.

*E.M.M. and N.K.C. contributed equally to this paper.

The authors declare no competing financial interests.

This article is freely available online through the J Neurosci Author Open Choice option.

Correspondence should be addressed to Andrew Trevelyan, Institute of Neuroscience, Medical School, Framlington Place, Newcastle upon Tyne, NE2 4HH, UK. E-mail: andrew.trevelyan@ncl.ac.uk.

DOI:10.1523/JNEUROSCI.4105-14.2015

Copyright $\odot 2015$ Alfonsa et al.

This is an Open Access article distributed under the terms of the Creative Commons Attribution License Creative Commons Attribution 4.0 International, which permits unrestricted use, distribution and reproduction in any medium provided that the original work is properly attributed. brain slices, resected to treat epilepsy, show evidence of excitatory GABAergic activity (Cohen et al., 2002; Pallud et al., 2014) associated with reduced expression of the potassium chloride cotransporter KCC2 (Huberfeld et al., 2007). Even without deficits in $\mathrm{KCC} 2$ expression, $\mathrm{Cl}^{-}$levels may rise acutely during intense GABAergic activation (Alger and Nicoll, 1979; FujiwaraTsukamoto et al., 2003; Isomura et al., 2003; Kaila, 1994; Kaila et al., 1997; Staley et al., 1995; Thompson and Gähwiler, 1989a,b,c) or be influenced by the distribution of other permeant and impermeant anions (Glykys et al., 2014). Collectively, these suggest an important role for chloride dysregulation in epileptogenesis, but it has not actually been shown whether raising intracellular $\mathrm{Cl}^{-}$generally within the neuronal population is sufficient by itself to trigger epileptiform events or what patterns of activity are associated with such $\mathrm{Cl}^{-}$loading.

The largest group of cortical neurons is the pyramidal population, representing $\sim 80 \%$ of all cortical neurons, and the timing of their firing is influenced strongly by the output of basket cells (Cobb et al., 1995). In epileptic cortical networks, there are particularly intense bursts of interneuronal activity that appear to provide a restraint on the propagation of epileptiform discharges (Prince and Wilder, 1967; Trevelyan et al., 2006; Schevon et al., 2012). We reasoned that chloride loading in the pyramidal population would strongly influence the pattern of any breakthrough firing during the high-frequency inhibitory volleys. In particular, we asked whether it might explain certain distinctive highfrequency features (Foffani et al., 2007; Ibarz et al., 2010) and firing patterns (Netoff and Schiff, 2002) associated with epileptic 
foci (Bragin et al., 2002a,b; Staba et al., 2002; Jiruska et al., 2010) and the onset of ictal activity. To test this, we made novel use of the enhanced optogenetic chloride pump derived from Natromonas, Halorhodopsin (eNpHR; Gradinaru et al., 2008) to artificially load pyramidal cells with chloride (Zhang et al., 2007; Raimondo et al., 2012) to examine the specific contribution of chloride dysregulation to epileptiform activity.

\section{Materials and Methods}

Dissociated neuronal culture recordings. All procedures were performed according to the requirements of the United Kingdom Animals (Scientific Procedures) Act 1986. Assessment of the chloride-loading effect of eNpHR activation was performed using dissociated neuronal cultures. Primary neuronal cultures were prepared from rat pups at embryonic days $18-20$ in the following way. A pregnant rat was killed by cervical dislocation, and a sagittal incision was made in the abdominal area to remove the pups. The neocortex and hippocampal tissue was isolated from the pups and digested using papain enzyme (Sigma-Aldrich) for $40 \mathrm{~min}$. Cells were then dissociated within the growing medium (Neurobasal A, 2\% B-27 supplement, 1\% FBS, 0.5\% glutamate, and $0.5 \%$ antibiotic-antimicotic; Invitrogen) by pipetting it up and down. Cells were plated $\left(10^{5}\right.$ cells $\left./ \mathrm{ml}\right)$ on coverslips coated with poly-Dlysine and laminin (Sigma-Aldrich). Cells were allowed to attach to the coverslips by incubating at $37^{\circ} \mathrm{C}$ for $2.5 \mathrm{~h}$. Cells were transfected using virus [human synapsin-eNpHR3.0-enhanced yellow fluorescent protein (EYFP)] at $7 \mathrm{~d}$ in vitro, and experiments were conducted on $14-28 \mathrm{~d}$ in vitro.

Optogenetic expression. All animal handling and experimentation were done according to United Kingdom Home Office guidelines. Optogenetic proteins were expressed on pyramidal cells by doing injection of viral vectors or breeding. To achieve pyramidal expression of eNpHR, we injected adeno-associated virus (AAV)-CaMKII-cre-GFP (University of North Carolina Viral Vector Core) into homozygous floxxed-eNpHR

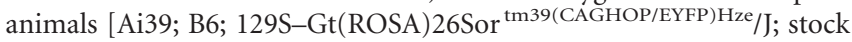
\#014539 The Jackson Laboratory]. For pyramidal expression of Archaerhodopsin (Arch), we injected AAV-CaMKIIa-eArchT3.0-EYFP (University of North Carolina Viral Vector Core) into wild-type C57BL/6J mice. Injections were made into either postnatal day $0-1$ pups or young adult mice. The pups had EMLA cream (2.5\% lidocaine and $2.5 \%$ prilocaine) applied to the left top of their head and were anesthetized subsequently using isoflurane inhalation. A single injection of virus was made using a $10 \mu \mathrm{l}$ Hamilton syringe, with a beveled 36 gauge needle (World Precision Instruments) $\sim 1 \mathrm{~mm}$ anterior to lambda and $1 \mathrm{~mm}$ lateral to the midline into the left hemisphere, at $1.7-0.8 \mathrm{~mm}$ deep to the skin (four separate $50 \mathrm{nl}$ injections, deepest first). Approximately $0.2 \mu \mathrm{l}\left(\sim 10^{11}-10^{12}\right.$ viral particles) was injected over a $10 \mathrm{~min}$ period. This reliably labeled pyramidal cells throughout the hemisphere and with minimal or no cortical scarring apparent from the injection tract at the time of recordings, at age 5 weeks to 3 months. This became the preferred method for labeling, but for the early experiments, we also performed injections in adult animals. For these adult injections, done at age 5-8 weeks, animals were anesthetized by ketamine-methoxamine intraperitoneal injection and placed in a stereotaxic head holder (David Kopf Instruments). Injections were made at three to four locations in an anterior-posterior row in one hemisphere, $1.5-2 \mathrm{~mm}$ lateral to the midline and 1-0.4 mm deep to the pia $(0.6 \mu \mathrm{l}$, injected over $15 \mathrm{~min})$. This gave far more restricted labeling, extending $0.2-0.5 \mathrm{~mm}$ in coronal slices, and the illumination and recordings were then targeted to the center of this area. We also used brain slices prepared from first-generation cross-breeding of floxxed-eNpHR animals with CaMKIIa-cre mice [B6.Cg-Tg(CaMK2a-cre)T29-1Stl/J; stock \#5359; The Jackson Laboratory]. The method of introducing eNpHR into pyramidal cells did not affect the pattern of activity induced by eNpHR priming.

Fluorescence immunocytochemistry. Adult male HaloGFP ${ }^{\mathrm{f} / \text {; CaMKcre }}$ mice were terminally anesthetized by brief inhalation of isoflurane $(0.05 \%$ in air), followed by an intramuscular injection of ketamine $(\geq 100 \mathrm{mg} / \mathrm{kg})$ and xylazine $(\geq 10 \mathrm{mg} / \mathrm{kg})$. Once anesthetized mice were perfused through the heart with $4 \%(\mathrm{w} / \mathrm{v})$ paraformaldehyde (PFA) in
PBS (0.1 M), pH 7.2. After perfusion, brains were removed and postfixed in $4 \%$ PFA in PBS overnight at $4^{\circ} \mathrm{C}$. The brain was cut coronally $(50-\mu \mathrm{m}-$ thick sections) using a Leica VT1000S vibratome. Sections were collected in PBS and then incubated in $50 \mathrm{~mm}$ ammonium chloride in PBS for 20 $\mathrm{min}$ at room temperature. After washing in PBS, sections were incubated in $0.1 \%(\mathrm{w} / \mathrm{v})$ gelatin and $0.1 \%(\mathrm{v} / \mathrm{v})$ Triton X-100 in PBS. Sections were double labeled with antibodies to eNpHR (rabbit anti-Halorhodopsin at 1:200; catalog \#AS12 1851; Agrisera) and interneuronal markers (sheep anti-neuropeptide $\mathrm{Y}$ at 1:1000, catalog \#AB1583, Millipore; goat antiparvalbumin at 1:1000, catalog \#PVG214, Swant; goat anti-somatostatin at 1:250, catalog \#sc7819, Santa Cruz Biotechnology). The antibodies were diluted in $0.1 \%(\mathrm{w} / \mathrm{v})$ gelatin and $0.1 \%(\mathrm{v} / \mathrm{v})$ Triton X-100 in PBS and incubated at $4^{\circ} \mathrm{C}$ for $48-72 \mathrm{~h}$. After extensive washing with PBS, sections were incubated with fluorescein isothiocyanate donkey antirabbit and Cy3 donkey anti-sheep and anti-goat secondary antibodies (Jackson ImmunoResearch) at a dilution of 1:500 in PBS for $2 \mathrm{~h}$ at room temperature. Finally, sections were washed extensively in PBS and mounted in VECTASHIELD HardSet mounting medium (Vector Laboratories). Control experiments, in which the primary antibodies were omitted, resulted in no immunoreactivity.

Double-labeling images were obtained by using a Leica TCS SP2 UV confocal microscope. For analysis, optical slices were reconstructed by using NIH ImageJ. The photomicrographs used in the figures were produced by first generating an extended depth of field projection of the z-stack by using NIH ImageJ. The brightness and contrast of each image were then optimized, and multipanel figures were composed and labeled by using Adobe Photoshop and Adobe Illustrator (Adobe Systems).

Brain slice experiments. Coronal brain slices $(250-\mu \mathrm{m}$-thick slices for perforated patch recordings and analysis of cellular excitability; $400 \mu \mathrm{m}$ for field recordings) were prepared from the injected animals (3-10 months) on ice-cold oxygenated $\left(95 \% \mathrm{O}_{2} / 5 \% \mathrm{CO}_{2}\right)$ artificial CSF (ACSF; in mm: $125 \mathrm{NaCl}, 26 \mathrm{NaHCO}_{3}, 10$ glucose, $3.5 \mathrm{KCl}, 1.26 \mathrm{NaH}_{2} \mathrm{PO}_{4}, 3$ $\mathrm{MgCl}_{2}, 1 \mathrm{Na}$-kynurenate, and $0.3 \mathrm{Na}$-ascorbate). For the perforated patch recordings, slices were simply transferred to a submerged incubation chamber for at least $1 \mathrm{~h}$ before recording. For the field recordings, after cutting, the slices were washed two times for $10 \mathrm{~min}$ with the oxygenated ACSF (in mm: $125 \mathrm{NaCl}, 26 \mathrm{NaHCO}_{3}, 10$ glucose, $3.5 \mathrm{KCl}, 1.26$ $\mathrm{NaH}_{2} \mathrm{PO}_{4}, 1.2 \mathrm{CaCl}_{2}$, and $1 \mathrm{MgCl}_{2}$ ) and transferred to an incubation, interface chamber (room temperature) perfused with the same ACSF for at least $1 \mathrm{~h}$ before being transferred to a recording interface chamber $\left(33-36^{\circ} \mathrm{C}\right)$ perfused with this same ACSF. The concentration of divalent cations was used following the study by Sanchez-Vivez and McCormick (1999), because this allowed the reliable triggering of sustained bursts of activity, with a prominent high-frequency discharge of fast-spiking interneurons, by white matter stimulation (putative thalamic inputs).

Perforated patch-clamp recordings. Recordings were made using a laser spinning disc confocal microscope (Visitech) fitted with Patchstar micromanipulators (Scientifica) mounted on a Scientifica movable top plate. Electrophysiological data were collected using Multiclamp 700B (Molecular Devices) and Digidata acquisition boards connected to desktop computers (Dell Computer Company) running pClamp software (Molecular Devices). During the entire recording, cells were bathed in circulating oxygenated ACSF solution (perfusion at $1-3 \mathrm{ml} / \mathrm{min}$ ), heated to $33-37^{\circ} \mathrm{C}$ by a sleeve heater element (Warner Instruments) around the inflow tube.

Gramicidin perforated patch recordings were made using 3-7 M $\Omega$ pipettes (borosilicate glass; Harvard Apparatus), pulled on a P87 Micropipette Puller (Sutter Instruments). Electrodes were filled with a highchloride internal solution [in mM: $135 \mathrm{KCl}, 4 \mathrm{Na}_{2} \mathrm{ATP}, 0.3 \mathrm{Na}_{3} \mathrm{GTP}, 2$ $\mathrm{MgCl}_{2}$, and 10 HEPES (290 mOsm), pH 7.35], so that the integrity of the cell membrane could be monitored. Fresh gramicidin stock was prepared daily at $5 \mathrm{mg} / \mathrm{ml}$ in DMSO (catalog \#G5002; Sigma-Aldrich). Gramicidin stock was added to the electrode filling solution to achieve a final concentration of $100 \mu \mathrm{l} / \mathrm{ml}$, mixed thoroughly (40 s vortexing and sonication), then filtered (Millex syringe filter, $0.45 \mu \mathrm{m}$ pore size), and used for patching immediately. Recordings were made when the series resistance had stabilized below $200 \mathrm{M} \Omega$ ( $\sim 30 \mathrm{~min}$ after patching).

Recordings were made in voltage-clamp mode, with a baseline holding potential of $-70 \mathrm{mV}$. $\mathrm{GABA}_{\mathrm{A}}$ currents were induced by $100 \mu \mathrm{M}$ muscimol application delivered close to the recorded neuron through a patch 
A Chloride loading

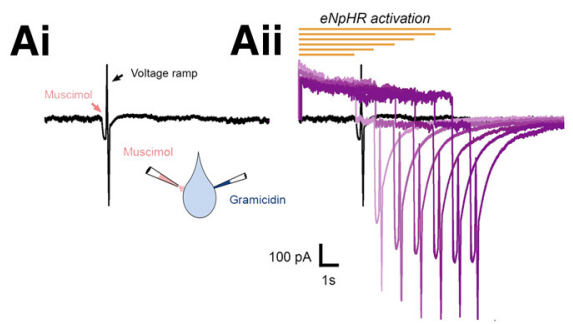

Aiii

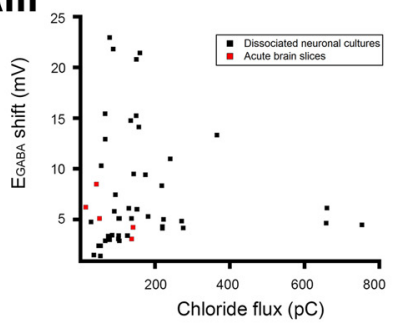

B Chloride decay

$\mathrm{Bi}$

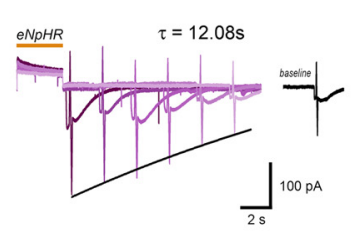

Bii

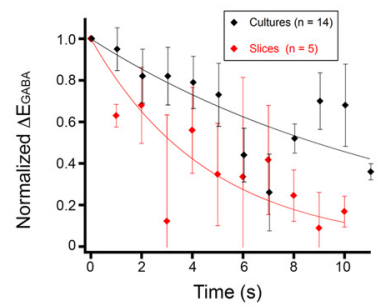

C Recovery of cellular attributes

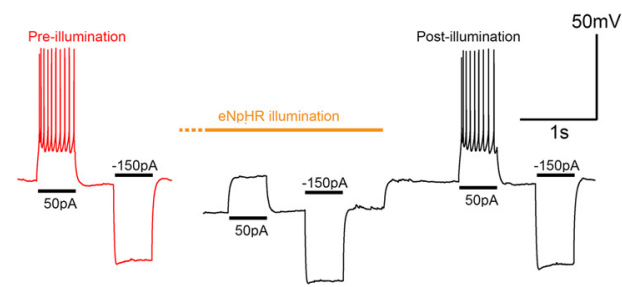

D

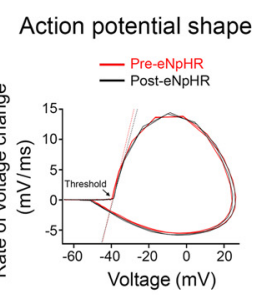

E Input resistance

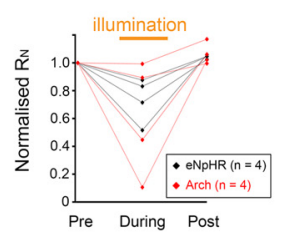

Figure 1. eNpHR chloride-loading effect. $\boldsymbol{A i}, E_{\mathrm{GABA}}$ was measured by doing perforated gramicidin patch recording and applying muscimol with or without previous eNpHR activation. Aii, Sample traces from a single neuron, showing progressively longer eNpHR activation, associated with a progressively larger effect on $E_{\mathrm{GABA}}$ as measured by a voltage ramp during a muscimol-triggered postsynaptic current. Aiii, $S$ Satter plot showing the shift in $E_{G A B A}$ versus the total loading charge calculated as the integral of the current over the illumination period. The plot includes multiple data points from single dissociated neurons, derived from different duration eNpHR activations ( $n$ cells) and five data points from five neurons (red) in adult brain slices, all from $2 \mathrm{~s}$ illumination. $\boldsymbol{B}$, The recovery of $E_{G A B A}$ after eNpHR activation. $\boldsymbol{B i}$, Sample traces from one of the neurons recorded in a brain slice, showing the response to muscimol puffs at progressively longer latencies after a $2 \mathrm{~s}$ eNpHR activation. A single-exponential curve (black line) is fitted to the minima of the voltage-ramp responses. Bii, Pooled data showing the recovery of $E_{G A B A}$ after eNpHR activation in dissociated neuron cultures (black) and neurons recorded in adult brain slices (red). Single-exponential fits of the mean data are shown, but note that the time constants reported in Results are the averages of fits made to each individual cell. C, Example trace showing the excitability, in response to somatic charge injection, of a layer 5 pyramidal cells recorded in an adult brain slice, before, during, and immediately after activation of eNpHR current (orange bar). $D$, Phase plots of the rate of voltage change (dV/dt) versus the voltage for AP doublets immediately before (red) and within $1 \mathrm{~s}$ after a $5 \mathrm{~s} \mathrm{eNpHR}$ activation (black), illustrating that eNpHR activation had no lasting effect on the AP threshold or shape. $\boldsymbol{E}$, Measures of input resistance $\left(R_{N}\right)$ normalized to the pre-optogenetic activation value, showing a pronounced drop during the optogenetic activation but a rapid recovery. The post-optogenetic measures were taken within $1 \mathrm{~s}$ of the end of the illumination period.

pipette coupled to a Picospritzer II (Parker Instrumentation) delivering $10 \mathrm{~ms}$ pressure pulses $(10-20 \mathrm{psi})$, and timing was coordinated with the illumination (optogenetic activation) using pClamp software coupled to a Digitizer box. Test voltage ramps (200 ms duration, a saw-tooth, updown function; peak, $-50 \mathrm{mV}$; trough, $-90 \mathrm{mV}$; slope, $\pm 400 \mathrm{mV} / \mathrm{s}$ ) were applied at baseline and also at close to the peak of GABAergic current $\left(I_{\mathrm{GABA}}\right)$. The GABAergic current, $I_{\mathrm{GABA}}$, was derived from the difference between the ramp currents to allow a GABAergic currentvoltage $(I-V)$ curve to be plotted. $I-V$ plots were derived with and without previous eNpHR activation, and the effect of eNpHR activation on $E_{\mathrm{GABA}}$ was estimated from the shift in the $x$-intercept of the $I-V$ plot. The time course of the chloride loading was measured by doing $2.8 \mathrm{~s}$ eNpHR activation, followed by muscimol puffs with increasing delay. The change in $E_{\mathrm{GABA}}$ was calculated for each time delay and normalized to the value for the shortest delay, and a single exponential curve was fitted to the normalized data to give the time constant for chloride clearance.

Recovery of cellular properties after optogenetic activation. Whole-cell patch-clamp recordings were made by direct visualization of neocortical pyramidal neurons (differential interference contrast microscopy). Cells were recorded in current-clamp mode (Multiclamp 700B and 1440 Digidata analog-to-digital board), and brief hyperpolarizing and depolarizing current pulses were applied before, during, and immediately after prolonged eNpHR or Arch activation to allow assessment of the input resistance and excitability parameters. The action potential (AP) threshold was estimated by fitting a straight line to the steepest part of the $\mathrm{dV} / \mathrm{dt}$ (first derivative of the voltage with respect to time) versus voltage phase plots and then extrapolating back to $0 \mathrm{dV} / \mathrm{dt}$ (Fig. 1C).

Field potential recordings. Early experiments were performed with sharp, glass microelectrodes, but to facilitate the spike sorting, we then turned to using tetrodes with four electrode heads in a diagonal arrangement separated by $50-100 \mu \mathrm{m}$ (NeuroNexus). Single-electrode extracellular recordings were made through broken-tip borosilicate patch pipettes (Harvard Apparatus), conducted using either Multiclamp 700B
(Molecular Devices) or Axoclamp 1D (Molecular Devices) amplifiers, a 1401-3 analog-to-digital converter (Cambridge Electronic Design), and Spike2 software (Cambridge Electronic Design) with sampling rate of 5-10 kHz. Multichannel extracellular recordings were collected at 10 $\mathrm{kHz}$, using a single four-channel-probe configuration (Q1x1-tet "tetrode"; NeuroNexus) connected to an ME16-FAI- $\mu$ PA system and MC_Rack software (Multichannel Systems). Bipolar electrical stimulation (0.2 ms duration) was delivered via tungsten electrodes onto the white matter. eNpHR and Arch were activated by $561 \mathrm{~nm}, 50 \mathrm{~mW}$ solidstate laser (Cobolt) connected to a fiber optic with a fine cannula (400 $\mu \mathrm{m}$ core, 0.20 numerical aperture; Thorlabs).

After optimizing the optic fiber coupling, the total light power at the cannula tip was measured at $15-30 \mathrm{~mW}$. To achieve an approximately equivalent inhibitory effect by the two different optogenetic probes, we then scaled down the illumination intensity until both gave an approximately equivalent suppression of the network response to a white matter electrical stimulation. This was measured at the same location as the subsequent post-illumination field effects. Typically, matching required slightly less light for the Arch than for the eNpHR experiments, consistent with our observations from single-cell recordings that Archtransfected neurons often showed larger light-activated currents. The illumination used in the recordings was constant in any given slice but ranged from 3 to $20 \mathrm{~mW}$ at the cannula tip to give equivalent suppression of the network event, as assessed by the line length of the unfiltered signal in the $0.5 \mathrm{~s}$ after the electrical artifact (Guo et al., 2010; eNpHR: mean reduction in line length of evoked event, $82.9 \pm 2.8 \%$; Arch: mean reduction, $88.5 \pm 4.4 \%$; not significant).

For the optogenetic illumination, to achieve illumination comparable hyperpolarization current (estimated by the suppression of electrical stimulation and the amplitude of the field recording artifact at the onset and offset of illumination), the light intensity was further reduced using neutral density filters (ND filters $0.2-0.6$; Thorlabs) placed in the light patch between the laser and the optic fiber. Our patch-clamp studies 
Ai

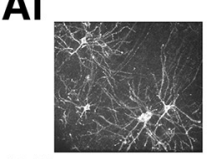

Aii

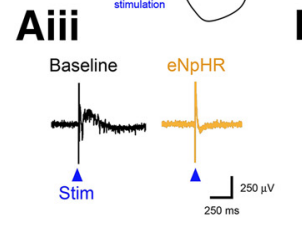

Bi

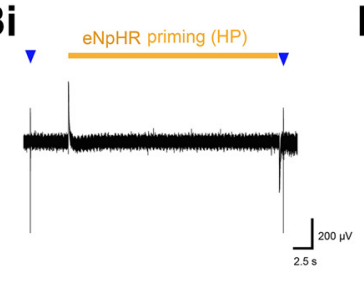

Biii

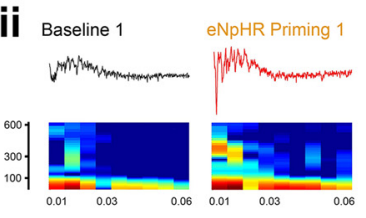

Bii
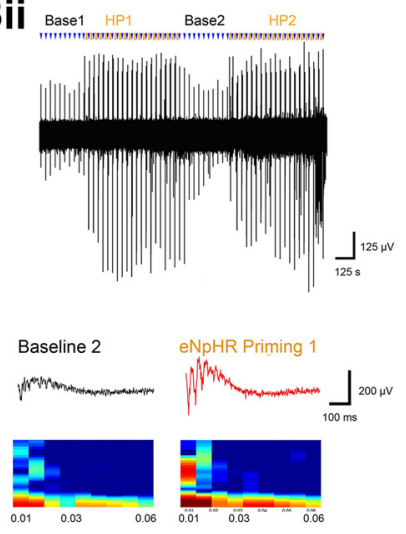

Ci

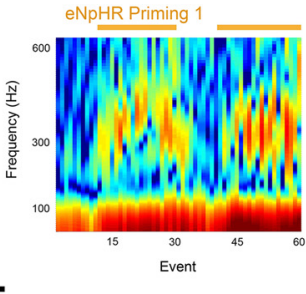

Cii

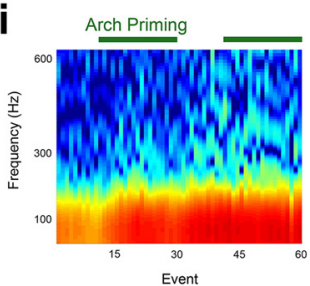

Figure 2. Halorhodopsin (Halo) chloride loading induces high-frequency oscillations. A, Network activity recording arrangement. Ai, Confocal image showing sparse expression of eNpHR-EYFP in pyramidal cells. Aii, schematic showing the locations of the recording electrode in layer 5 (gray), stimulating electrode (blue) in the underlying white matter, and a fiber optic delivering $560 \mathrm{~nm}$ wavelength light. Aiii, $560 \mathrm{~nm}$ greatly suppresses the electrically evoked neural activity, thereby demonstrating the existence of a prominent eNpHR current. $\boldsymbol{B}$, Sample recordings showing the effect of repeated $25 \mathrm{~s}$ periods of $560 \mathrm{~nm}$ illumination to activate eNpHR (eNpHR priming), with electrical stimulation during the dark periods ( $5 \mathrm{~s}$ ). Electrical stimulation was applied $0.5 \mathrm{~s}$ after and $4.5 \mathrm{~s}$ before the illumination. The interval between stimuli was always $30 \mathrm{~s}$. Baseline periods had the same electrical stimulation frequency (period, $t=30 \mathrm{~s}$ ) but no eNpHR illumination. Bii, Representative traces and spectrograms taken during two periods of electrical stimulation without eNpHRillumination (Base1 and Base2) and two periods with illumination (HP1 and HP2). Note the large increase in power at $300-600 \mathrm{~Hz}$ during the eNpHR-priming periods, which reversed rapidly without illumination (Base2 and Ci). C, Composites of sequential spectrograms to show the changes during the entire experiment. Note the prominent band at $\sim 200-500 \mathrm{~Hz}$, indicative of a rise in high-frequency power induced by eNpHR priming and the reversion to baseline without illumination. Similar experiments with Arch induced a small increase in amplitude of the network event but without any change in the high-frequency activity.

showed that a more stable optogenetic current could be obtained by coillumination of both 561 and $491 \mathrm{~nm}$ light, thought to be attributable to improved cis-to-trans recovery of the activated retinal by blue light (Han and Boyden, 2007). Therefore, we provided coillumination of the brain slices, using the $561 \mathrm{~nm}$ laser light with blue epifluorescence light ( $460 \pm 20 \mathrm{~nm}$ excitation filter) through a $4 \times$ air objective $(0.28$ numerical aperture; Nikon). We confirmed that this coillumination strategy provided an enhanced and sustained eNpHR current by assessing the suppressive effect on electrical stimulation at different times during a long illumination period.

Spike-timing analyses. Frequency band analysis and all the spectrograms were done on the raw data, whereas for single-unit and multiunit analyses, bandpass filter of $300-5000 \mathrm{~Hz}$ was applied and spikes were detected by a simple thresholding algorithm. Spike analyses were only performed for periods when the tissue was not illuminated (that is to say, not during the periods of optogenetic activation). To analyze spike timing according to the dominant oscillation, detected spikes were plotted on the Hilbert transform of the corresponding dominant oscillation in the 75-300 Hz bandpass. Angle and linear histograms were derived from the Hilbert plot. Baseline data were centralized and fitted to a Gaussian curve to obtain the baseline half-width. To assess the AP jitter and outof-phase firing across multiple experiments, we derived a "half-width index," which was calculated using the following formula:

$$
\text { Half-width index }=\frac{\sum(\text { spikes outside baseline HW })}{\sum(\text { spikes within baseline HW })}
$$

where HW is the half-width measured on the baseline period. Note that the baseline HW is used for all analyses for a single experiment, including for the optogenetically primed datasets that have a different width modal histogram peak.

Computer simulations of firing patterns. Modeling was performed to provide a simple, intuitive illustration of the phenomenon we describe in our experimental studies, showing the consequence of changing $E_{\mathrm{GABA}}$ in a conductance-based model neuron. All the simulations presented here were run on personal computers (Dell Computer Company) using the NEURON simulation program (Hines and Carnevale, 2001). We will provide the main model files on request but will describe their features below.

All simulations were run on simple four-compartment models possessing a soma, an axon, and a single dendrite comprising a short proximal compartment and a long distal one. The passive properties were homogeneous throughout the cells [membrane capacitance, $1 \mu \mathrm{F} / \mathrm{cm}^{2}$; axial resistivity, $160 \Omega \mathrm{cm}$; leak conductance $\left(g_{\text {leak }}\right), 0.66 \mathrm{pS} / \mu \mathrm{m}^{2} ; g_{\text {leak }}$ reversal potential, $-80.6 \mathrm{mV}$; resting membrane potential, $-76 \mathrm{mV}]$. The input resistance in the passive structure (also zero synaptic conductance) was relatively high $(\sim 1 \mathrm{G} \Omega)$, primarily because of the relatively small structure of the cell, but the membrane time constant (passive $\tau_{0}=$ $\sim 27 \mathrm{~ms}$ ) was consistent with that measured in layer $2 / 3$ pyramidal cells at physiological temperature (Trevelyan and Jack, 2002). All model cells had the same somatic and axonal active conductances: a HodgkinHuxley-type $\mathrm{Na}^{+}$conductance (peak conductance, $2000 \mathrm{pS} / \mu \mathrm{m}^{2}$ ) and two non-inactivating $\mathrm{K}^{+}$conductances (peak conductance, 5 and 3.5 $\mathrm{pS} / \mu \mathrm{m}^{2}$, respectively).

Ten excitatory synaptic conductances $\left(E_{\text {rev }}=0 \mathrm{mV}\right)$ were located on the distal compartment, spaced equally along its length, providing a persistent, noisy excitatory drive of mean $6.4 \mathrm{pS} / \mu \mathrm{m}^{2}$ (calculated over the entire distal dendritic compartment) with a variance of $10 \%$. This noisy excitatory drive was implemented as described by Destexhe et al. (2001) and reduced the input resistance to $\sim 170 \mathrm{M} \Omega$. In the absence of inhibition, this generated a high rate of spiking, with no periodicity (see Fig. $4 A$ ). Threshold for AP generation was $-57.7 \mathrm{mV}$.

Inhibitory synapses were located only on the proximal dendritic tree to simulate the powerful basket cell inputs that are known to dictate pyramidal spike timing (Cobb et al., 1995). Because our intention was only to explore the constraint of pyramidal firing by basket cells, we did not include other inhibitory synapses in our models. Basket cells were set to fire at $100 \mathrm{~Hz}$ and deliver a steady amplitude train of postsynaptic conductance events. Each synaptic event was modeled as a transient conductance, described by a rising time constant $\left(\tau_{\text {rise }}=0.2 \mathrm{~ms}\right)$ and a decay time constant $\left(\tau_{\text {decay }}=2.5 \mathrm{~ms}\right)$ as follows:

$$
g=W \cdot\left(\exp \left(-t / \tau_{\text {decay }}\right)-\exp \left(-t / \tau_{\text {rise }}\right)\right),
$$

where $g$ is the conductance, and $W$ is the synaptic weight, giving a peak conductance of $15.9 \mathrm{pS} / \mu \mathrm{m}^{2}$ over the whole proximal dendritic compartment. We ran separate simulations for a range of $E_{\mathrm{GABA}}$ values from -45 to $-85 \mathrm{mV}$. At $100 \mathrm{~Hz}$, and the mean conductance was $4.86 \mathrm{pS} / \mu \mathrm{m}^{2}$ across the whole compartment. Consistent with experimental models, our simulations showed that this high-frequency proximal dendritic inhibition imposed very clear phase relation on the times of pyramidal firing for all values of $E_{\mathrm{GABA}}$, with respect to the rhythm of the basket cell firing. We will make the NEURON code available freely on request. 
A

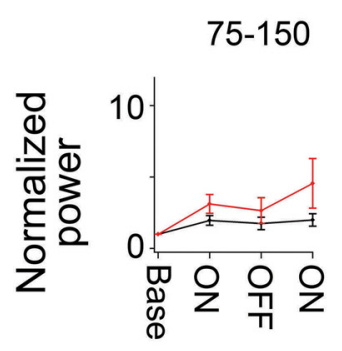

Frequency $(\mathrm{Hz})$

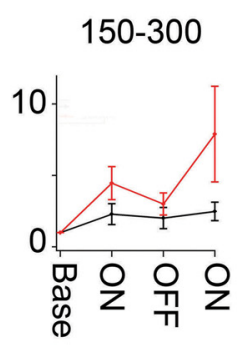

$300-600$

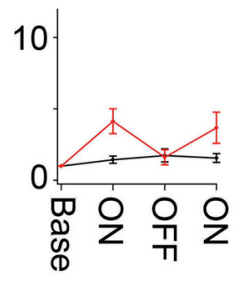

B

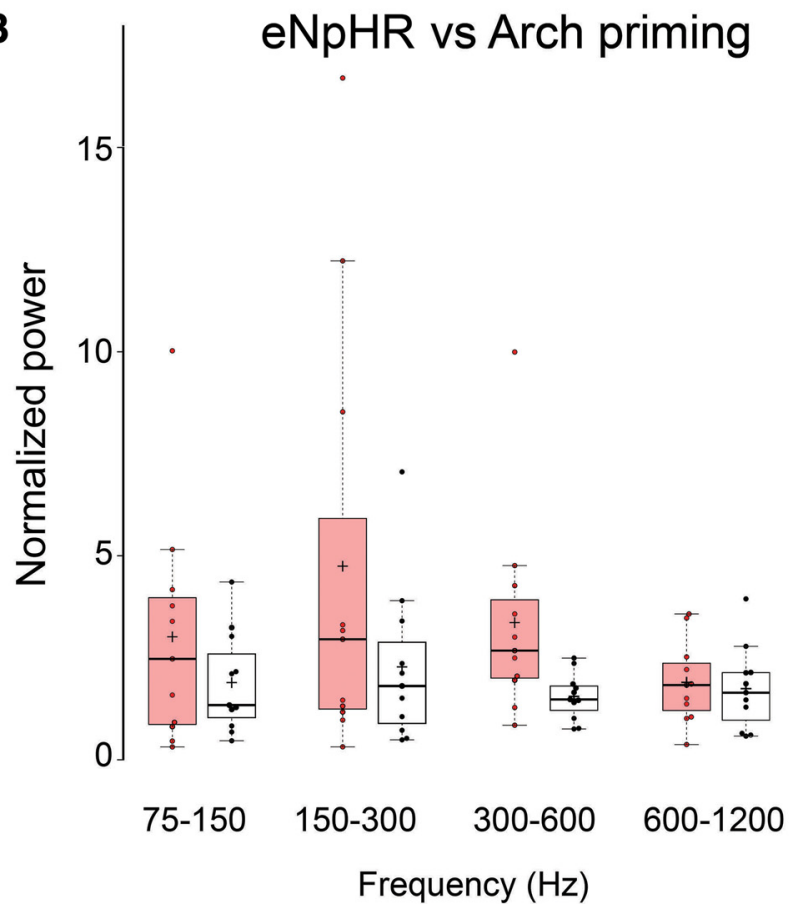

Figure 3. Frequency analysis of eNpHR-priming versus Arch-priming experiments. $\boldsymbol{A}$, Pooled averages over all experiments, showing the changes in spectral power for different frequency bands, normalized to the baseline for each recording, for epochs of repeated eNpHR primed (red) and Arch primed (black; ON and intermediary periods without illumination (OFF). $\boldsymbol{B}$, Box plot of the averaged $0 N$-period power during eNpHR priming and Arch priming for different frequency bands. eNpHR activation positively modulates activity across all frequency bands but only differs significantly from Arch activation in the $300-600 \mathrm{~Hz}$ frequency band ( $n=11$ for eNpHR and Arch, $p<0.01, t$ test). Halo, Halorhodopsin.

The simulations of the population firing were made by convolving the spike-phase plots with histograms of $E_{\mathrm{GABA}}$ values for two distributions, one taken from Huberfeld's measures (mean $E_{\mathrm{GABA}}=-60.8 \mathrm{mV}$; Huberfeld et al., 2007) and a second "normal" distribution that was shifted in a hyperpolarizing direction (mean $E_{\mathrm{GABA}}=-68.5 \mathrm{mV}$ ). We made eight simulations of the spike-phase plots for values of $E_{\mathrm{GABA}}$ between -80 to $-45 \mathrm{mV}$ ( $5 \mathrm{mV}$ steps) and multiplied each distribution by the number of cells in that bin before normalizing the plots to give an ordinate axis in terms of the probability of a spike per bin per cycle.

Offline analysis was done using Igor (WaveMetrics), MATLAB (MathWorks), and Microsoft Excel software. Box plots were generated using online software (http://boxplot.tyerslab.com). Statistics are given as mean \pm SEM unless otherwise stated, and significance is tested using paired Student's $t$ tests.

\section{Results}

Transient chloride loading of neurons using optogenetics Perforated patch recordings of dissociated pyramidal cells in culture indicated that activation of eNpHR for just a few seconds could induce positive shifts in $E_{\mathrm{GABA}}$ of up to $25 \mathrm{mV}$ (Fig. 1A),
$600-1200$

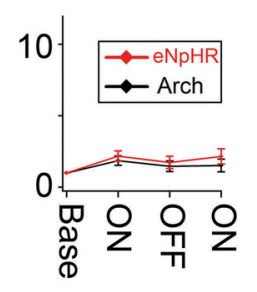

confirming previous work by Raimondo et al. (2012). The shift in $E_{\mathrm{GABA}}$ decayed back to baseline levels with a time constant, $\tau_{\text {decay }}$ of $28.12 \pm 9.26 \mathrm{~s}$ ( $n=14$; Fig. $1 B)$. We repeated these experiments also on pyramidal cells in brain slices prepared from adult mice ( 5 months) and showed a qualitatively similar effect $\left(\tau_{\text {decay }}=8.0 \pm\right.$ $2.8 \mathrm{~s} ; n=5)$. Notably, both groups showed large variance in the calculated time constants, indicating some degree of heterogeneity with respect to this cellular behavior, and consequently, although the averages suggested that the decay was faster in brain slices, the difference from the cultured neurons was not significant in our samples $\left(t_{\mathrm{s}}=1.36 ; 0.2<p<0.3\right)$. Importantly, other cellular parameters affecting neuronal excitability returned rapidly to normal after the end of eNpHR activation. In whole-cell current-clamp recordings of pyramidal cells recorded in brain slices prepared from adult mice, we induced eNpHR activation, causing an average hyperpolarizing shift of $23.0 \pm 1.5$ $\mathrm{mV}$, strongly suppressing firing driven by current injection and also inducing a $27 \pm$ $8 \%$ drop in input resistance. Measurements taken within the first second after the end of eNpHR activation showed no difference from the preillumination measures for resting membrane potential (pre-eNpHR $E_{\mathrm{m}}=-74.8 \pm 2.5 \mathrm{mV}$; posteNpHR $E_{\mathrm{m}}=-75.0 \pm 2.9 \mathrm{mV} ; n=4$ cells), input resistance (Fig. 1C; change from baseline, $4.4 \pm 1.4 \%$ ), and AP threshold [pre-eNpHR threshold (above $\left.E_{\mathrm{m}}\right), 33.0 \pm 1.2 \mathrm{mV}$; post-eNpHR threshold, $33.3 \pm 1.2 \mathrm{mV} ; n=4]$, height (peak - threshold: pre, $53.9 \pm 4.4 \mathrm{mV}$; post, $52.9 \pm 4.5 \mathrm{mV} ; n=4$ ), or shape (Fig. $1 D)$. At this same time point, $E_{\mathrm{GABA}}$ was shifted positively by $5.9 \pm 1.0 \mathrm{mV}$ in cultures $(n=12$ cells $)$ and $3.9 \pm 0.6 \mathrm{mV}$ in adult pyramidal cells $(n=4$ cells) in acutely prepared brain slices (culture vs slice comparison: $t_{\mathrm{s}}=$ $1.09 ; 0.4<p<0.2$, nonsignificant). In short, the only apparent cellular change persisting beyond $1 \mathrm{~s}$ was the change in $E_{\mathrm{GABA}}$.

We made similar measurements after Arch activation. This optogenetic protein also hyperpolarizes neurons but by pumping protons out of cells. As with eNpHR activation, Arch activation was associated with a suppression of firing and a drop in input resistance (normalized to preillumination, $R_{\mathrm{n}}=61 \pm 20 \%, n=$ 4 ), but these both corrected rapidly within a second of ending illumination (post-illumination, normalized $R_{\mathrm{n}}=106 \pm 4 \%$ ), as did baseline $E_{\mathrm{m}}$ (pre, $-71.1 \mathrm{mV}$; post, $-70.6 \mathrm{mV} ; n=4 ; t_{\mathrm{s}}=0.03$, n.s.), AP threshold relative to baseline $E_{\mathrm{m}}$ (pre, $32.1 \pm 4.2 \mathrm{mV}$; post, $32.5 \pm 4.3 \mathrm{mV} ; n=4 ; t_{\mathrm{s}}=0.02$, n.s.), and AP height (peak threshold: pre, $56.2 \pm 6.7 \mathrm{mV}$; post, $54.9 \pm 7.0 \mathrm{mV} ; n=4 ; t_{\mathrm{s}}=$ 0.13 , n.s.). However, unlike after eNpHR activation, Arch activation produced no change in $E_{\mathrm{GABA}}$ (measured at $\sim 1 \mathrm{~s}$ after illumination; pre, $-64.5 \pm 5.1 \mathrm{mV}$; post, $-64.7 \pm 5.5 \mathrm{mV} ; n=3$; $t_{\mathrm{s}}$ 


\section{A eNpHR-priming}

Baseline
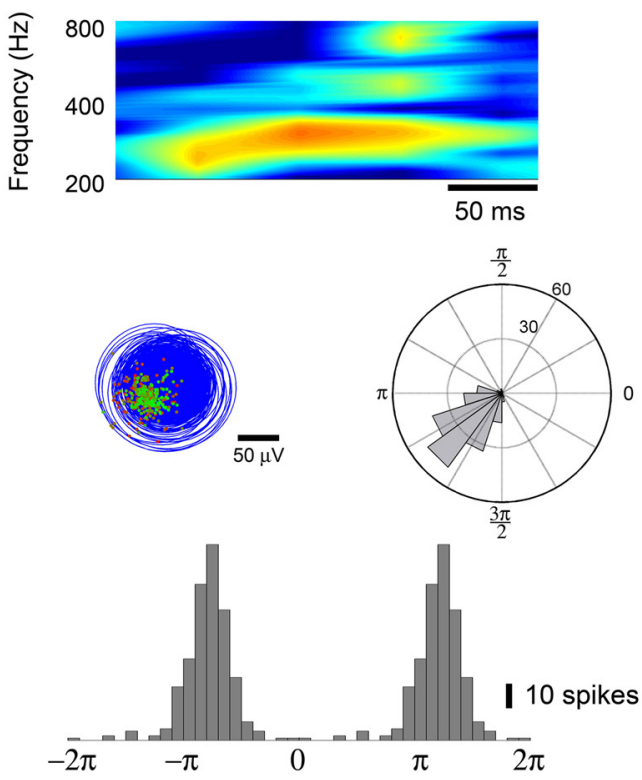

\section{B Arch priming}

\section{Baseline}

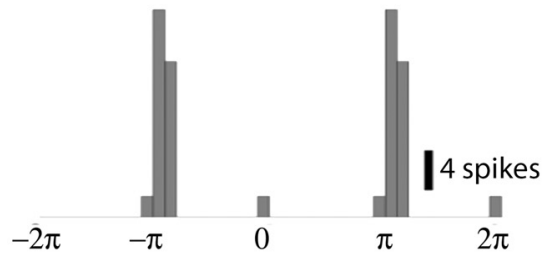

eNpHR primed
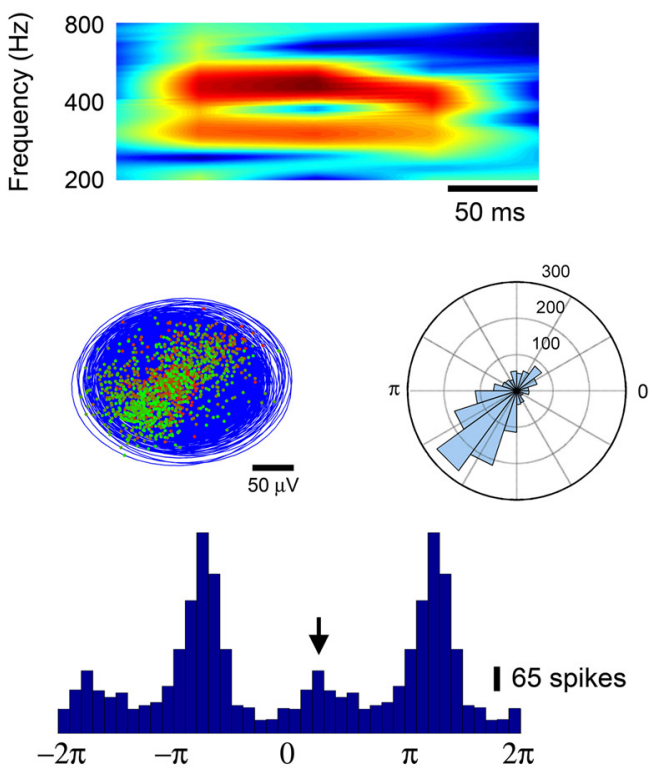

C

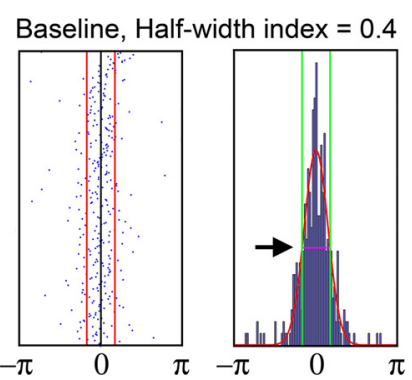

eNpHR-primed, Half-width index $=1.1$

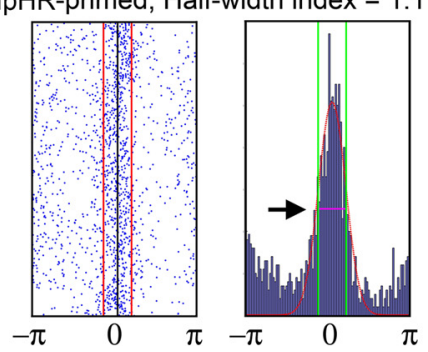

D
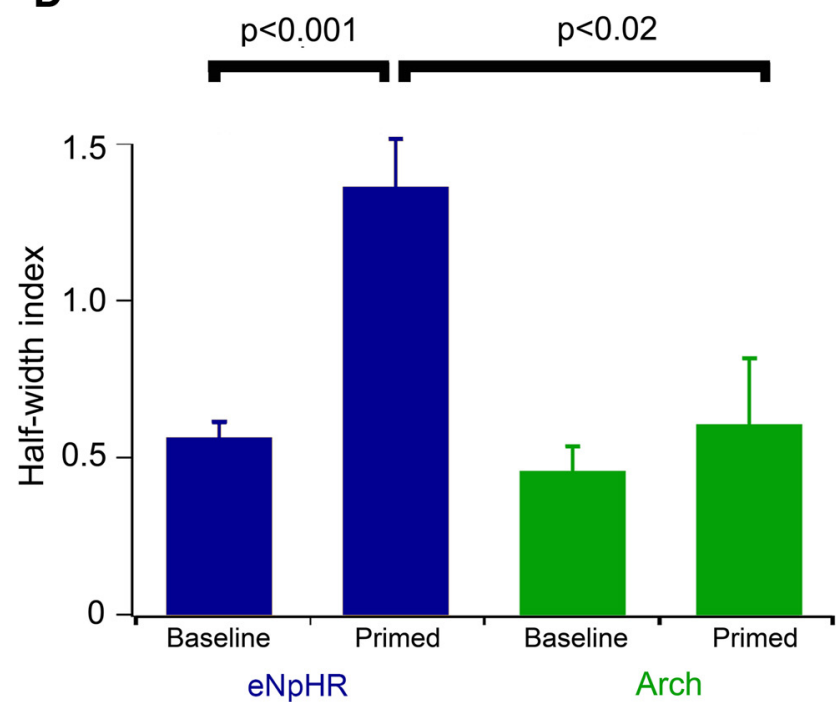

Figure 4. Neuronal chloride loading triggers out-of-phase firing during spontaneous bursts of activity. A, Spectrograms of extracellular recordings of spontaneous bursts of activity in baseline (left) and eNpHR-primed (chloride-loaded) tissue. Note the prominent "double-frequency" signal in the chloride-loaded tissue. Detected spikes [dots, red (early) to green (Figure legend continues) 
$=0.02$, n.s.), consistent with previous reports (Raimondo et al., 2012).

Thus, eNpHR activation can non-invasively induce a transient loading of $\mathrm{Cl}^{-}$into many neurons simultaneously through broad illumination of networks expressing the protein. Therefore, we used this technique to modulate intraneuronal $\mathrm{Cl}^{-}$levels in pyramidal cells in brain slices to investigate what patterns of activity ensue when neurons become loaded with $\mathrm{Cl}^{-}$, as is thought to happen in epileptic pathology.

We recorded neocortical activity patterns in brain slices taken from animals expressing either eNpHR or Arch (Chow et al., 2010), both under the CaMKII $\alpha$ promoter (Fig. 2). We used a methodology developed by Sanchez-Vives and McCormick (2000), in which the extracellular divalent cation concentration is lowered slightly $\left(1.2 \mathrm{mM} \mathrm{Ca}^{2+}, 1 \mathrm{mM} \mathrm{Mg}^{2+}\right)$, because this allowed the reliable triggering of sustained bursts of activity, with a prominent discharge of fast-spiking interneurons (Shu et al., 2003), by white matter stimulation (putative thalamic inputs). We first confirmed that activation of the optogenetic probe, by illumination through an optic fiber placed adjacent to the recording electrode, could suppress substantially the electrically evoked network response (Fig. 2Aiii). We then changed the timing of electrical stimulation so that it was delivered after the optogenetic activation to investigate the chloride-loaded state induced by eNpHR priming. Prolonged eNpHR activation might also induce rebound firing simply as a reaction to the hyperpolarization. Therefore, we repeated these experiments in brain slices expressing instead Arch, which is another hyperpolarizing optogenetic tool that pumps protons out and which thus allows us to separate the chloride-loading effects from the rebound activation.

\section{Distinctive network activity induced by chloride loading}

Chloride loading the pyramidal population, by previous eNpHR activation ("eNpHR priming"), reliably induced a large increase in evoked network activity with a prominent signal in highfrequency bandwidth between 150 and $600 \mathrm{~Hz}$. This effect reversed rapidly, within five trials (150 s), once eNpHR priming was stopped (Figs. $2 B, C, 3 A$ ). In contrast, after Arch priming, there was no change in the high-frequency power from baseline trials, confirming that the eNpHR-primed induced highfrequency activity is $\mathrm{Cl}^{-}$dependent and not merely attributable to rebound firing caused by synchronized hyperpolarization of pyramidal cells (Figs. 2C, $3 A, B$ ). We performed more detailed analysis of the high-frequency components of the extracellular signal between 75 and $600 \mathrm{~Hz}$. The eNpHR-primed tissue showed increases above that shown by Arch-primed tissue at all frequencies, but this was only significantly different for the $300-600 \mathrm{~Hz}$

\footnotetext{
(Figure legend continues.) (late) shows a progression of time] were plotted on the Hilbert transform of the dominant oscillation $(75-300 \mathrm{~Hz}$; blue circular trace), and the rose plots represent the numbers of APs occurring at different phases of the oscillation. Note the out-of-phase spiking in the eNpHR-primed dataset, also apparent as a second minor peak (arrowed) in the conventional histogram (duplicated data beyond $-\pi$ and $\pi$ ). B, Periods of hyperpolarization using Arch (Arch-priming) causes a rebound increase in spiking (contrast the calibration bars for the histograms) but no change in the phase distribution of spikes. C, Half-width index measured the ratio between the number of out-of-phase spikes to the in-phase spikes, which were taken to be the spikes within bounds (red lines) set by the half-width of a Gaussian fit to the main spike peak in the baseline histograms. Left column shows the raster plots for baseline and Cl-loaded tissue, and the right column shows the same data plotted as histograms of the spike times. $\boldsymbol{D}$, Pooled data for half-width indices, showing significantly higher values for Cl-loaded slices (eNpHR-primed) compared with baseline ( $n=8, p<0.001, t$ test) and for Arch-primed tissue $(n=6, p<0.02, t$ test). Halo, Halorhodopsin.
}

bin [Fig. 3A; first priming, eNpHR (4.13 $\pm 0.87, n=11)$ vs Arch $(1.44 \pm 0.26, n=11), p<0.01$; second priming, eNpHR (3.67 \pm $1.09, n=7)$ vs Arch $(1.56 \pm 0.31, n=10), p<0.05$, Student's $t$ test]. The $600-1200 \mathrm{~Hz}$ signal showed virtually no change for either eNpHR- or Arch-primed tissue, indicating that the eNpHR-priming effect at $300-600 \mathrm{~Hz}$ is unlikely to arise simply from a signal harmonic process, because that would have also produced increases at higher-order harmonics, too.

Previous studies of high-frequency oscillations in epileptic rats suggested that they arise from out-of-phase firing between subpopulations of pyramidal cells (Foffani et al., 2007; Ibarz et al., 2010). Therefore, we conducted analysis of spontaneous spiking in the periods between optogenetic activation (Fig. 4). Analysis was conducted on the periods after the end of the evoked burst of activity and before the subsequent optogenetic illumination (10 4.5 -s epochs, 45 s total per slice). After eNpHR priming, there was a significant increase in the multiunit firing rate (note the different scale bars in Fig. $4 B$; baseline multiunit rate, $6.7 \pm 2.5$ spikes/s; eNpHR-primed, $38.3 \pm 6.6$ spikes/s; $n=8 ; p<0.001$; eNpHR-priming increase, normalized to baseline, $12.7 \pm 4.8$ ). In contrast, Arch-priming produced only a small, but nonsignificant, trend toward increased firing over baseline (Arch baseline multiunit rate, $6.5 \pm 1.9$ spikes/s; Arch-primed, $10.2 \pm 2.6$ spikes/s; $n=6$; n.s.; Arch-priming increase, $2.2 \pm 0.7$ ).

In both baseline and eNpHR-primed periods, there were episodes of bursting activity that showed up as prominent bands in the spectrograms between 150 and $300 \mathrm{~Hz}$ (Fig. 4A), with an additional band at approximately double this frequency after eNpHR priming (Fig. 4A, right). We speculated that the lowerfrequency bandwidth $(<300 \mathrm{~Hz})$ may be dictated by bursts of fast-spiking interneurons, which are known to fire in this range, and because the output of these neurons can entrain pyramidal firing, we analyzed the timing of the multiunit activity with respect to the dominant frequency band between 75 and $300 \mathrm{~Hz}$. We did this by performing a Hilbert transform on the $75-300 \mathrm{~Hz}$ band, which allows the oscillating signal to be plotted as a continuous circular trajectory, and then plotting histograms of the spike times with respect to this cycle (Fig. $4 A$ ). Spiking during the baseline period was virtually entirely confined to the lower left quadrant (eNpHR-expressing tissue: mean phase angle, $3.58 \pm$ $0.11 \mathrm{Rad}, n=7$; Arch-expressing tissue: mean phase angle, $3.24 \pm 0.14 \mathrm{Rad}, n=6$ ), which represented spikes occurring close to the trough of the local field potential. In contrast, after eNpHR priming, the spiking was far more intense, spike timing showed a marked increase in jitter with respect to the dominant high gamma oscillations in all slices, and, in three of eight slices, there was a biphasic distribution, with a prominent peak in the histogram exactly out-of-phase with the main peak. This feature was unique to the eNpHR-priming experiments and did not occur with Arch priming (Fig. 4B).

To pool data from different experiments, we derived an outof-phase index by fitting a Gaussian curve centered on the circular mean to define the half-width of the modal peak and then calculating the ratio of the number of spikes outside of this halfwidth limit to the number of spikes within it (Fig. 4C). This showed a highly significant increase in out-of-phase spiking in the eNpHR-primed tissue (half-width index, $1.35 \pm 0.15, n=8$ ) compared with both baseline periods $(0.56 \pm 0.04, n=8, p<$ $0.001)$ and also to the control Arch-primed tissue $(0.60 \pm 0.20$, $n=6, p<0.02$; Fig. $4 D$ ).

An important consideration when analyzing such spike-phase relationships, especially when relating units and field recordings made in the same electrode, is spectral leak, which is when a very 
A Raw signal with / without spikes

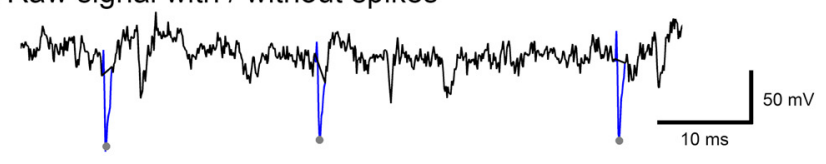
B $75-300 \mathrm{~Hz}$ signal
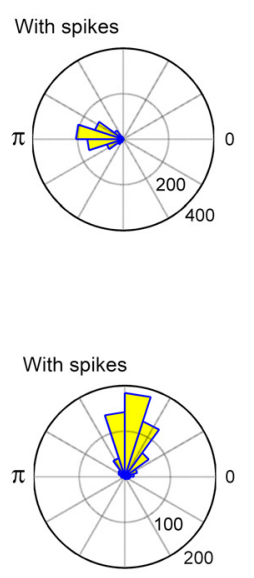
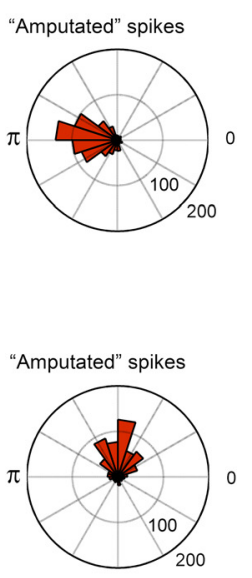

C Time shifted spikes on $75-300 \mathrm{~Hz}$ signal with soikes $\rightarrow 0-$
amputated $\rightarrow-\infty$

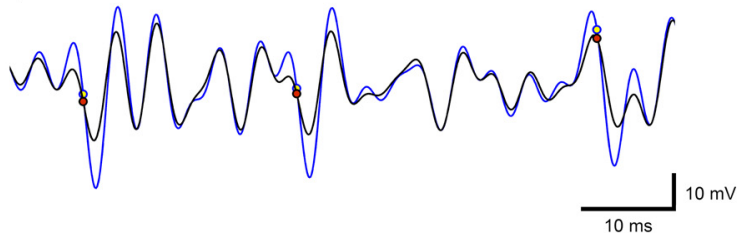

Figure 5. Control analyses to examine the effect of spectral leak. A, A raw data trace, showing the spikes (blue) and the amputated version (black). The bottom traces show the $75-300 \mathrm{~Hz}$ bandpass filtered traces. $\boldsymbol{B}, 75-300 \mathrm{~Hz}$ bandpass filtered traces of the raw (blue) and the amputated traces. Red dots indicate the spike times. Note the reduced amplitude peaks for the amputated spikes but that these still occur at the same phase of the oscillation, as evidence by the same skewed orientation of the pooled data shown in the spike-phase plots (right columns). $\boldsymbol{C}$, The same filtered traces but showing the new locations of APs for the time-shifted analysis. The spike-phase plots showed a shifted phase, reflecting the time shift, and a broader main peak, but importantly, they were still heavily skewed for both the raw and amputated data.

A
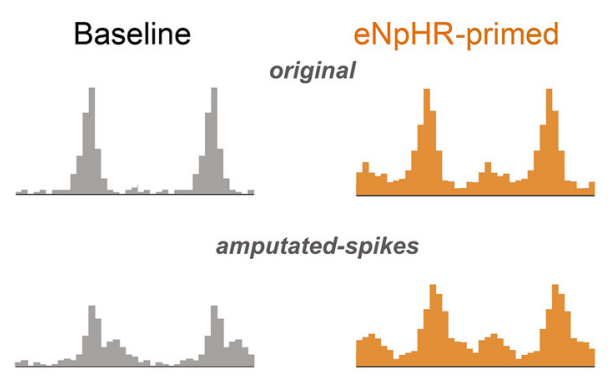

time-shift

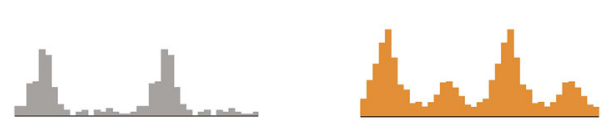

amputated-spikes \& time-shift

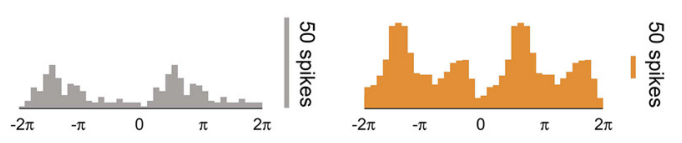

B

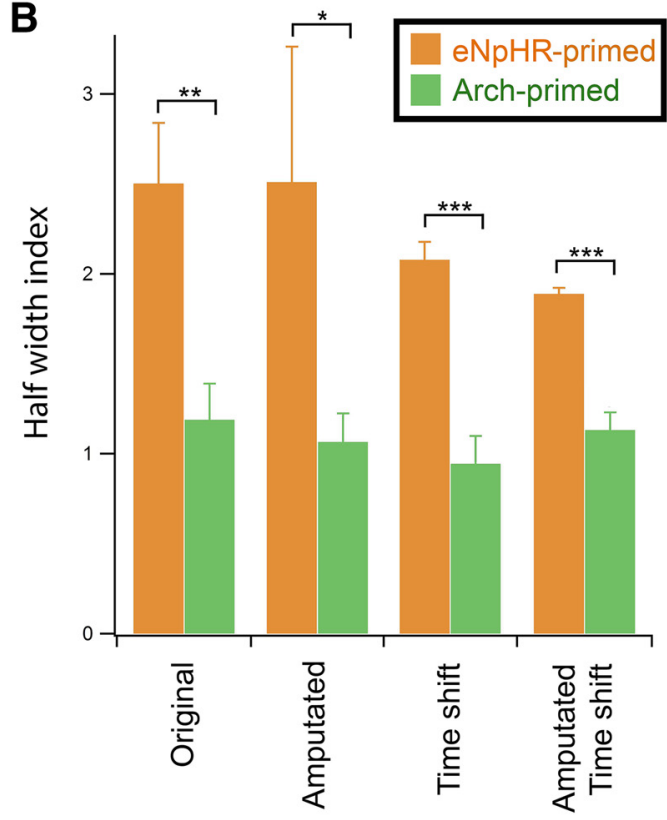

Figure 6. Spike-phase relationships were preserved for three different control analyses for spectral leak effects. $\boldsymbol{A}$, Example phase histograms showing the shifted spike-phase distributions for the three control paradigms illustrated in Figure 5 , but note that the key features, with baseline spike-phase plots having single peaks, and eNpHR-primed plots having double peaks, are maintained. $\boldsymbol{B}$, Pooled data showing that there were highly significant differences between the eNpHR-primed and Arch-primed matched analyses for all control paradigms. ${ }^{*} p<0.05 ;{ }^{* *} p<0.01 ;{ }^{* * *} p<$ 0.001. Halo, Halorhodopsin.

high-frequency event will create a small oscillation also in lower bandpass filtered traces. To separate the spectral leak from the spike-independent field oscillation, we therefore performed two control analyses to examine potential confounding effects of spectral leak. First, we performed amputations of the unit spikes in the raw data before performing the $75-300 \mathrm{~Hz}$ filtering (Fig. 5).
This reduced the amplitudes of the peaks (Fig. 5A, contrast the blue and black lines), and the spike-phase distributions showed slightly broader peaks than for the normal signal, both indicating that there was indeed a small spectral leak effect, but importantly, the distribution remained strongly skewed. We further tested the confounding influence of spectral leak with a second more ex- 


\section{A Simulated firing patterns}

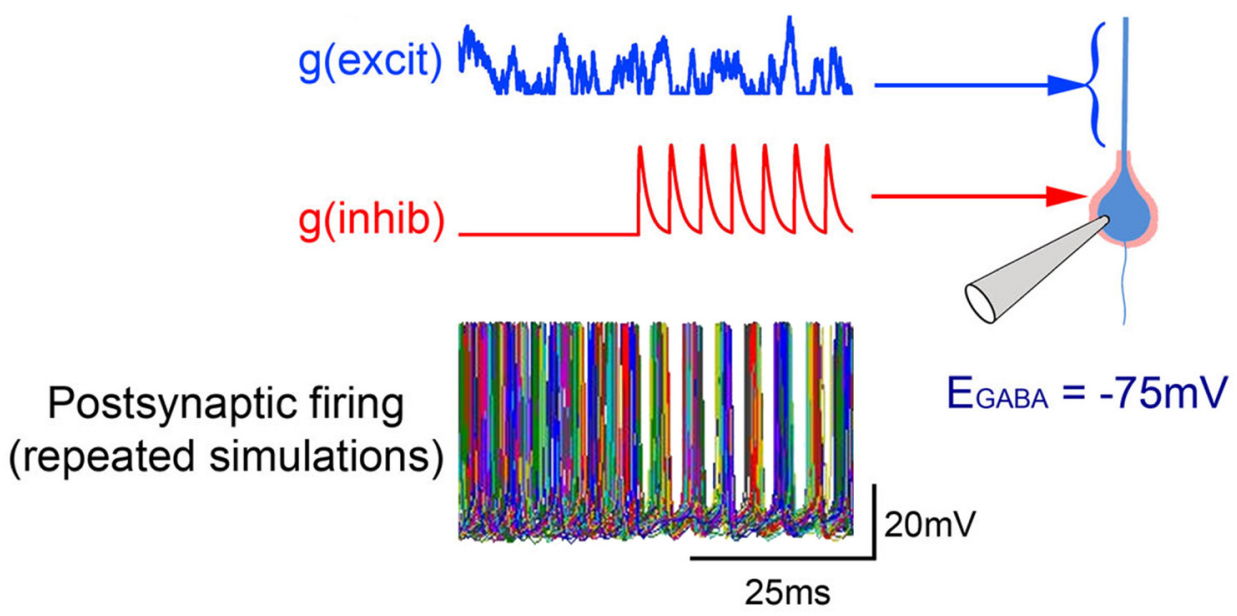

\section{B Firing phase relations}

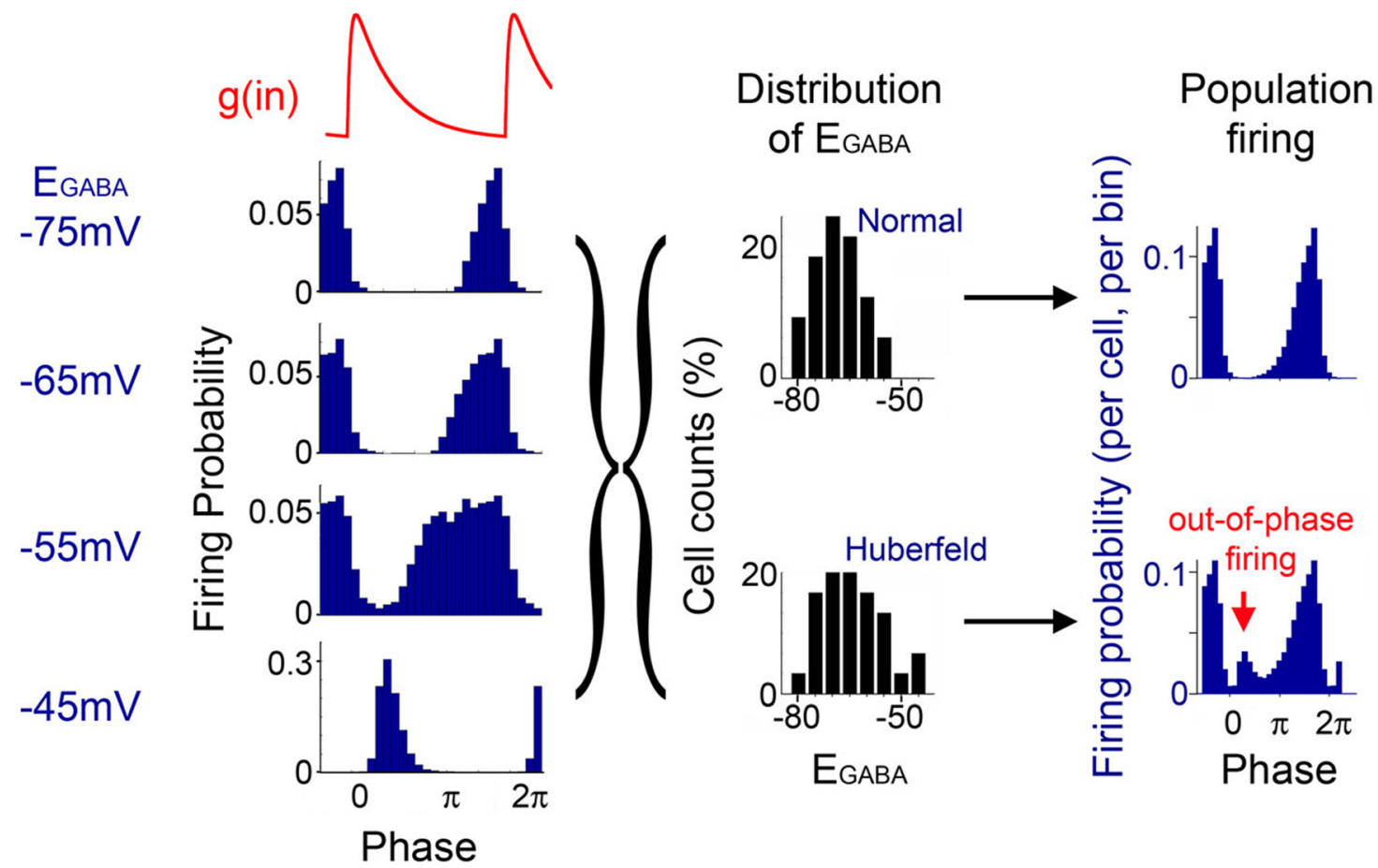

Figure 7. Heterogeneity in levels of intracellular $\mathrm{Cl}^{-}$can explain the appearance of out-of-phase population firing. $A$, Simulation using NEURON of how a train of high-frequency IPSCs from a fast-spiking interneuron superimposed onto a noisy, desynchronized glutamatergic drive creates a patterned firing in the pyramidal cell. AP threshold was approximately $-48 \mathrm{mV}$. B, Simulations in the same model, at four different GABAergic reversal potentials. The firing probability is plotted with respect to the field oscillation, which is approximately $\pi / 4$ phase shifted from the start of the IPSC, as judged by comparisons with the timing of fast-spiking interneuron APs (Hasenstaub et al., 2005). These different probability histograms are convolved with estimates of the distribution of $E_{G A B A}$ in the pyramidal population [middle, black; the bottom histogram is taken from the study of Huberfeld et al. (2007), mean $E_{G A B A}=-64 \mathrm{mV}$; the top is a simulated, normal distribution shifted to a slightly more hyperpolarized mean $\left.E_{\mathrm{GABA}}=-68 \mathrm{mV}\right]$. The convolution is achieved by assuming that the various bins show the firing phase relations in the left plots, to yield estimates of the population firing for the "normal" and the "Huberfeld" populations.

treme test by examining the phase relationship at a time ahead of the spikes. Our reasoning was that, if the spikes were indeed embedded within genuine oscillations, then these oscillations would extend sufficiently far in front and after the spike that the relationship would still exist for time-shifted points. We chose a forward time shift to avoid any postsynaptic influences. We tested increasing $\Delta t$ until the amputated and non-amputated spike-phase plots were identical, indicating a time point beyond the effect of the spikes. The $\Delta t$ was specific for each trace and ranged between 1.3 and $1.8 \mathrm{~ms}$ ahead of the spike. Importantly, for all three analyses [(1) amputated; (2) time-shifted; and (3) both amputated and shifted data], the baseline and Arch-primed datasets produced single-peak phase distribu- 

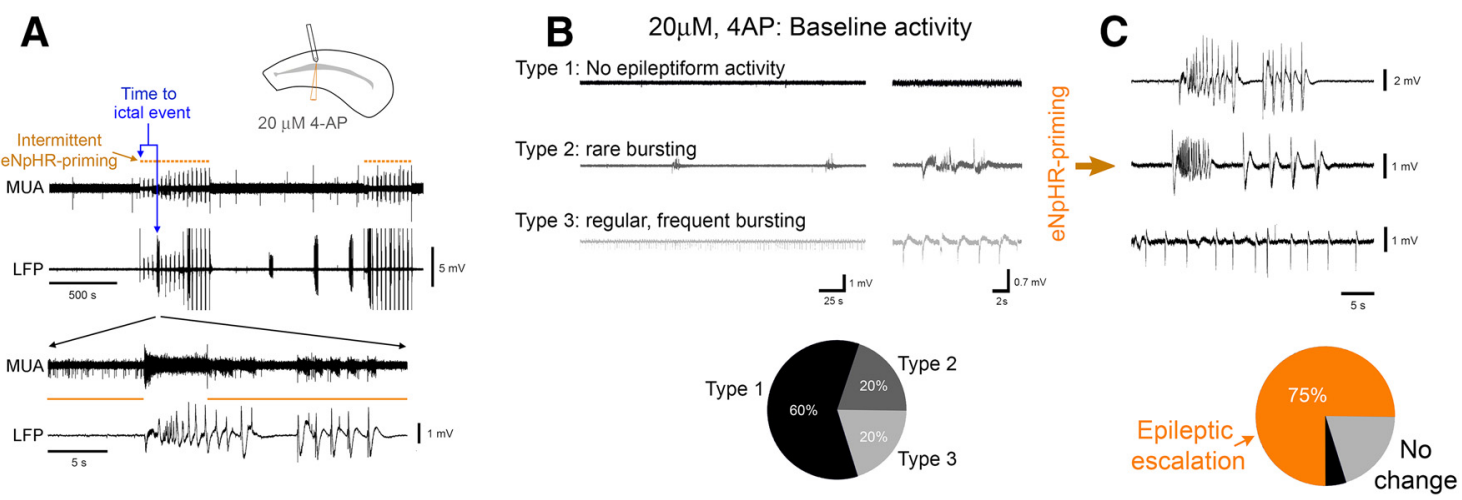

Figure 8. Rapid escalation of epileptiform activity by eNpHR priming in conjunction with 4-AP. A, Multiunit activity (MUA; $300-5000 \mathrm{~Hz}$ ) and local field potential (LFP; 1-300 Hz) recordings showing a full ictal event occurring after just four periods of illumination in a slice bathed in $20 \mu \mathrm{m}$ 4-AP. The top two traces show the entire recording, and the bottom two show a zoomed in view of an epileptiform discharge that starts immediately after the end of a period of eNpHR-activation (orange bar). Note how the event persists even when the illumination (eNpHR activation) is resumed. $\boldsymbol{B}$, Example traces showing three initial patterns of activity in $20 \mu \mathrm{m}$ 4-AP before eNpHR activation: Type 1, no evidence of any epileptiform activity (12 of 20; black trace); Type 2, occasional brief and small-amplitude interictal events (middle trace, dark gray; $n=4$ ); and Type 3, continual frequent discharges starting within minutes of applying 4-AP ("status epilepticus"; bottom trace, light gray; $n=4)$. C, eNpHR activation caused a rapid escalation of epileptiform activity, with the appearance of sustained epileptiform bursts (full ictal events) in 15 of 16 ( $94 \%$ ) of the recordings that initially showed Type 1 (non-epileptic) and Type 2 (interical events only) activity. Type 3 activity was not obviously modulated by eNpHR activation, persisting also through periods of illumination without changing frequency or amplitude. Halo, Halorhodopsin.

tions, whereas the eNpHR-primed datasets produced double peaks (Fig. 6). We derived half-width indices for all three analyses, which all showed highly significant differences between eNpHR-primed and baseline periods and also between the eNpHR-primed and Arch-primed data (Fig. 6). Therefore, we concluded that, although there is indeed a small but demonstrable spectral leak effect, this could not explain the distinctive spike-phase plots found in the different experiments.

\section{Activity patterns explained by heterogeneity within the Cl- loaded pyramidal population}

We hypothesized that a mechanism involving fast-spiking interneurons, which are known to influence the timing of pyramidal neurons and are also thought to discharge at high rates in response to surges in network activity (Cammarota et al., 2013), might explain these spiking patterns. In particular, we investigated how the influence of a high frequency inhibitory barrage might be distorted by changing the intracellular $\mathrm{Cl}^{-}$levels in the postsynaptic population, using compartmental neuronal modeling (Hines and Carnevale, 2001). We simulated an intense, desynchronized glutamatergic drive on to a pyramidal cell and then further delivered a high-frequency barrage of IPSCs on to the soma and proximal dendrites; Figure $7 A$ shows repeated simulations of postsynaptic spiking for a cell with a relatively hyperpolarizing $E_{\mathrm{GABA}}$ $(-75 \mathrm{mV})$, which are collated into spiking phase histograms based on the cycle of IPSCs. We next simulated how the effect of this same inhibitory barrage changed with $E_{\mathrm{GABA}}$ shifting toward more positive levels (Fig. $7 B$ ) to show that the window of opportunity for pyramidal spiking broadens as the effective inhibition diminishes ( $E_{\mathrm{GABA}}$ shifting from -75 to -65 to $-55 \mathrm{mV}$ ). Eventually, when $E_{\mathrm{GABA}}$ exceeds AP threshold (more than $-48 \mathrm{mV}$ ), there is a sudden $180^{\circ}(\pi)$ phase shift in the spiking.

Previous studies have shown that the output of fast-spiking interneurons is synchronized precisely on to the multiple postsynaptic pyramidal cells (Miles et al., 1996; Trevelyan, 2009). If we consider that this postsynaptic population has a distribution of $E_{\mathrm{GABA}}$ values, as measured by Huberfeld et al. (2007) and also shown using $\mathrm{Cl}^{-}$imaging (Dzhala et al., 2010), we can use the simulations of firing patterns for the single cell at different $E_{\mathrm{GABA}}$ levels to simulate the multiunit spiking patterns in this heteroge- neous population. We derived the population response using two different distributions of $E_{\mathrm{GABA}}$ values, one distribution as described in resected human epileptic hippocampi (Huberfeld et al., 2007) and a negatively shifted one as the physiological distribution. The physiologically shifted distribution (mean $E_{\mathrm{GABA}}=$ $-68.5 \mathrm{mV}$; Fig. $7 B$, top right) showed a unimodal spiking distribution with respect to the rhythm imposed by the basket cells. In contrast, only a small positive shift in $E_{\mathrm{GABA}}$ (mean $E_{\mathrm{GABA}}=-60.8$ $\mathrm{mV}$; Fig. $7 B$, bottom right) allowed a marked increase in spiking because of the broadening of the main peak but also the appearance of a prominent out-of-phase peak, reflecting the activity of the subpopulation of neurons with pathologically high levels of $\mathrm{Cl}^{-}$and a correspondingly high $E_{\mathrm{GABA}}$, in excess of AP threshold. These distributions reproduced very well the histograms drawn from different eNpHR-primed brain slices (Fig. 4A).

\section{$\mathrm{Cl}^{-}$loading only triggered full ictal events in conjunction with other pathological activity}

This model thus provides a coherent explanation of how our eNpHR-priming experiments can give rise to activity patterns that have also been described in epileptic animals (Foffani et al., 2007; Ibarz et al., 2010). Therefore, it was a surprise that, in none of these experiments, either with eNpHR or Arch priming, did repeated electrical stimulation to the network actually trigger ictal-like events, with hypersynchronous, rhythmic discharges. We next asked whether $\mathrm{Cl}^{-}$loading altered the seizure threshold for other treatments. We examined the 4-aminopyridine (4-AP) model, because this model is known to trigger intense bursts of firing in the fast-spiking interneuronal population (Cammarota et al., 2013), therefore reasoning that such activity may escalate toward ictal activity if their postsynaptic output were imposed on a population of pyramidal cells with raised intracellular $\mathrm{Cl}^{-} \mathrm{lev}_{-}$ els. Epileptiform activity can be readily induced by bath application of 50-100 $\mu \mathrm{M} 4$-AP in brain slices. When we used only $20 \mu \mathrm{M}$ 4-AP, 4 of 20 slices showed epileptiform activity very quickly $(<10 \mathrm{~min})$, and this activity was not in any way modulated by subsequent eNpHR activation (Fig. 8). The majority of slices were quiescent $(80 \%)$, even when bathed in $20 \mu \mathrm{M}$ for $>1 \mathrm{~h}$. However, when these quiescent slices were then eNpHR primed, full ictal activity was very rapidly induced, within a few minutes, 
in all but a single slice [ 15 of 16 slices; latency to the first full ictal event after start of eNpHR priming, $8.9 \pm 2.7$ cycles ( 30 s cycles of $25 \mathrm{~s}$ illumination $/ 5 \mathrm{~s}$ dark); latency from the start of the first cycle, $268 \pm 80 \mathrm{~s}, n=15$; Fig. $8 B$ ]. The ictal activity generally started immediately after the light was turned off, without the need of electrical stimulation, and often persisted into the next illumination cycle, resisting the inhibitory action of the eNpHR (see the expanded example traces in Fig. 8A).

\section{Discussion}

We explored a key hypothesis in epilepsy: that chloride dysregulation in neurons is a major factor in triggering seizures. Surprisingly, $\mathrm{Cl}^{-}$loading by itself did not trigger full ictal activity, even when electrical stimulation was delivered to the network. However, when $\mathrm{Cl}^{-}$loading was associated with other pathological activation, by bathing in low levels of 4-AP, it did rapidly induce ictal activity. Thus, we make a clear distinction between how $\mathrm{Cl}^{-}$ loading creates a primed brain state and the requirement for some adjunct pathology to actually trigger a seizure.

Previous animal work has suggested that intense bursts of GABAergic activity can themselves be a direct trigger of seizures, with the proposed mechanism being a positive shift in $E_{\mathrm{GABA}}$ (Bernard et al., 2000; Gnatkovsky et al., 2008). An important component of the pathology may be that this pattern of inhibitory discharge can synchronize the postsynaptic population of pyramidal cells (Klaassen et al., 2006). These issues are explored further in several review articles (Menendez de la Prida and Trevelyan, 2011; Jiruska et al., 2013). Our results suggest that the combination of such intense interneuronal discharges together with a progressive shifting $E_{\mathrm{GABA}}$ may be particularly ictogenic and also give rise to certain previously unexplained features of electrophysiological recordings immediately before the seizure onset.

Our findings have a clear parallel with recent studies of human brain tissue resected during epilepsy surgery (Cohen et al., 2002; Huberfeld et al., 2007; Pallud et al., 2014), which show spontaneously occurring interictal events when bathed in conventional ACSF. These interictal events are sensitive to GABAergic blockade, suggestive of a $\mathrm{Cl}^{-}$-loaded, excitatory GABAergic state, but to trigger full ictal events in these slices required excitability to be further enhanced by bathing in raised $\mathrm{K}^{+}$. Importantly, the subsequent ictal activity appeared to arise out of a fundamentally different type of transient discharge that was not sensitive to GABAergic blockade (Pallud et al., 2014). In other words, as with our data, we can distinguish between interictal activity associated with $\mathrm{Cl}^{-}$dysregulation and a second pattern of pathological activity that is independent of $\mathrm{Cl}^{-}$dysregulation; the combination of these is associated with full ictal activation, but the first alone does not predispose to full ictal events.

We contrasted the immediate changes in network excitability after eNpHR priming versus Arch priming. We attempted to achieve an approximately equivalent suppressive effect of network activation by Arch and eNpHR by adjusting the illumination intensity. Of course this is rather inexact, but the key issue is that, in both optogenetic paradigms, we clearly achieved some measurable network suppression, and then our data collection focused on the residual, post-illumination effects, of which the change in $E_{\mathrm{GABA}}$ appeared to be the most persistent. After activation of both eNpHR and Arch, there was a rise in excitability, suggesting that rebound activation may contribute, but the effect was far larger for eNpHR priming. Importantly, there were other, highly distinctive changes in firing patterns induced by eNpHR priming that are well captured by a model of a heterogeneous $\mathrm{Cl}^{-}$ loading in the population of pyramidal cells, causing them to react differently to the same high-frequency, GABAergic, synaptic barrage. The eNpHR-priming network changes also reversed with a timeframe similar to the recovery of $E_{\mathrm{GABA}}$ measured in single cells. Collectively, this strongly suggests that the eNpHRpriming effect identifies unique features of network excitability attributable to $\mathrm{Cl}^{-}$loading.

These changes in activity in the $\mathrm{Cl}^{-}$-loaded tissue correspond well with activity patterns recorded in epileptic animals (Foffani et al., 2007; Ibarz et al., 2010) in that both show particular highfrequency field oscillations with an apparent harmonic feature. The activity in the epileptic animals has been explained in terms of individual neurons firing at lower rates but with different subpopulations of neurons firing out-of-phase with each other. Our $\mathrm{Cl}^{-}$-loading experiments support this view, and our model explains how this binary segregation could occur, depending on whether $E_{\mathrm{GABA}}$ is below or above the AP threshold in different cells. The important feature of this model is that there is a distribution of $E_{\mathrm{GABA}}$ values, and, in this situation, the eNpHRpriming effect can arise with relatively small (single figure millivolt changes) shifts in the mean $E_{\mathrm{GABA}}$.

There is an increasing body of evidence that links highfrequency oscillations to the focus of epileptic pathology in humans, too (Bragin et al., 2002b; Staba et al., 2002). There are, of course, other mechanisms suggested for the origin of highfrequency oscillations, albeit without this "harmonic" feature. Any intense, focal activation of large numbers of neurons will generate a high-frequency signal, and there are several paradigms of epileptiform activity in which this occurs independent of any fast-spiking interneuron involvement. For instance, epileptic activity may arise from local loss of inhibition or even in preparations without synaptic function (Draguhn et al., 1998), in which ephaptic (Jiruska et al., 2010) or gap junction-mediated (Traub et al., 1999) spread has been implicated. However, our data provide the first evidence that there may be characteristic features of highfrequency activity that are pathognomonic for $\mathrm{Cl}^{-}$dysregulation. It should further prompt us to look for other features that may also be used to subclassify pathological activity patterns, particularly if they also offer insights into the underlying pathology.

Our model also pertains to another long-time puzzle about epileptic spiking patterns, which is that, as the cortical network is recruited to a full ictal event, there is an increase in spiking jitter between neurons (Netoff and Schiff, 2002). This result had seemed to contradict the traditional concept of a progression toward hypersynchrony, but our data now offer an explanation, suggesting, instead, that the progressive trend is with the shift in $E_{\mathrm{GABA}}$, and a consequence of this is that the initial apparent effect is that the spiking window is made broader, before the critical stage is reached when $E_{\mathrm{GABA}}$ surpasses $\mathrm{AP}$ threshold.

\section{References}

Alger BE, Nicoll RA (1979) GABA-mediated biphasic inhibitory responses in hippocampus. Nature 281:315-317. CrossRef Medline

Bernard C, Cossart R, Hirsch JC, Esclapez M, Ben-Ari Y (2000) What is GABAergic inhibition? How is it modified in epilepsy? Epilepsia 41 [Suppl 6]: S90-S95.

Bragin A, Mody I, Wilson CL, Engel J Jr (2002a) Local generation of fast ripples in epileptic brain. J Neurosci 22:2012-2021. Medline

Bragin A, Wilson CL, Staba RJ, Reddick M, Fried I, Engel J Jr (2002b) Interictal high-frequency oscillations $(80-500 \mathrm{~Hz})$ in the human epileptic brain: entorhinal cortex. Ann Neurol 52:407-415. CrossRef Medline

Cammarota M, Losi G, Chiavegato A, Zonta M, Carmignoto G (2013) Fast spiking interneuron control of seizure propagation in a cortical slice model of focal epilepsy. J Physiol 591:807-822. CrossRef Medline

Chow BY, Han X, Dobry AS, Qian X, Chuong AS, Li M, Henninger MA, Belfort GM, Lin Y, Monahan PE, Boyden ES (2010) High-performance 
genetically targetable optical neural silencing by light-driven proton pumps. Nature 463:98-102. CrossRef Medline

Cobb SR, Buhl EH, Halasy K, Paulsen O, Somogyi P (1995) Synchronization of neuronal activity in hippocampus by individual GABAergic interneurons. Nature 378:75-78. CrossRef Medline

Cohen I, Navarro V, Clemenceau S, Baulac M, Miles R (2002) On the origin of interictal activity in human temporal lobe epilepsy in vitro. Science 298:1418-1421. CrossRef Medline

Cossart R, Bernard C, Ben-Ari Y (2005) Multiple facets of GABAergic neurons and synapses: multiple fates of GABA signalling in epilepsies. Trends Neurosci 28:108-115. CrossRef Medline

Destexhe A, Rudolph M, Fellous JM, Sejnowski TJ (2001) Fluctuating synaptic conductances recreate in vivo-like activity in neocortical neurons. Neuroscience 107:13-24. CrossRef Medline

Draguhn A, Traub RD, Schmitz D, Jefferys JG (1998) Electrical coupling underlies high-frequency oscillations in the hippocampus in vitro. Nature 394:189-192. CrossRef Medline

Dzhala VI, Kuchibhotla KV, Glykys JC, Kahle KT, Swiercz WB, Feng G, Kuner T, Augustine GJ, Bacskai BJ, Staley KJ (2010) Progressive NKCC1dependent neuronal chloride accumulation during neonatal seizures. J Neurosci 30:11745-11761. CrossRef Medline

Foffani G, Uzcategui YG, Gal B, Menendez de la Prida L (2007) Reduced spike-timing reliability correlates with the emergence of fast ripples in the rat epileptic hippocampus. Neuron 55:930-941. CrossRef Medline

Fujiwara-Tsukamoto Y, Isomura Y, Nambu A, Takada M (2003) Excitatory gaba input directly drives seizure-like rhythmic synchronization in mature hippocampal CA1 pyramidal cells. Neuroscience 119:265-275. CrossRef Medline

Glykys J, Dzhala V, Egawa K, Balena T, Saponjian Y, Kuchibhotla KV, Bacskai BJ, Kahle KT, Zeuthen T, Staley KJ (2014) Local impermeant anions establish the neuronal chloride concentration. Science 343:670-675. CrossRef Medline

Gnatkovsky V, Librizzi L, Trombin F, de Curtis M (2008) Fast activity at seizure onset is mediated by inhibitory circuits in the entorhinal cortex in vitro. Ann Neurol 64:674-686. CrossRef Medline

Gradinaru V, Thompson KR, Deisseroth K (2008) eNpHR: a Natronomonas halorhodopsin enhanced for optogenetic applications. Brain Cell Biol 36:129-139. CrossRef Medline

Guo L, Rivero D, Dorado J, Rabuñal JR, Pazos A (2010) Automatic epileptic seizure detection in EEGs based on line length feature and artificial neural networks. J Neurosci Methods 191:101-109. CrossRef Medline

Han X, Boyden ES (2007) Multiple-color optical activation, silencing, and desynchronization of neural activity, with single-spike temporal resolution. PLoS One 2:e299. CrossRef Medline

Hasenstaub A, Shu Y, Haider B, Kraushaar U, Duque A, McCormick DA (2005) Inhibitory postsynaptic potentials carry synchronized frequency information in active cortical networks. Neuron 47:423-435. CrossRef Medline

Hines ML, Carnevale NT (2001) NEURON: a tool for neuroscientists. Neuroscientist 7:123-135. CrossRef Medline

Huberfeld G, Wittner L, Clemenceau S, Baulac M, Kaila K, Miles R, Rivera C (2007) Perturbed chloride homeostasis and GABAergic signaling in human temporal lobe epilepsy. J Neurosci 27:9866-9873. CrossRef Medline

Ibarz JM, Foffani G, Cid E, Inostroza M, Menendez de la Prida L (2010) Emergent dynamics of fast ripples in the epileptic hippocampus. J Neurosci 30:16249-16261. CrossRef Medline

Isomura Y, Sugimoto M, Fujiwara-Tsukamoto Y, Yamamoto-Muraki S, Yamada J, Fukuda A (2003) Synaptically activated $\mathrm{Cl}-$ accumulation responsible for depolarizing GABAergic responses in mature hippocampal neurons. J Neurophysiol 90:2752-2756. CrossRef Medline

Jiruska P, Csicsvari J, Powell AD, Fox JE, Chang WC, Vreugdenhil M, Li X, Palus M, Bujan AF, Dearden RW, Jefferys JG (2010) High-frequency network activity, global increase in neuronal activity, and synchrony expansion precede epileptic seizures in vitro. J Neurosci 30:5690-5701. CrossRef Medline

Jiruska P, de Curtis M, Jefferys JG, Schevon CA, Schiff SJ, Schindler K (2013) Synchronization and desynchronization in epilepsy: controversies and hypotheses. J Physiol 591:787-797. CrossRef Medline

Kaila K (1994) Ionic basis of GABAA receptor channel function in the nervous system. Prog Neurobiol 42:489-537. CrossRef Medline

Kaila K, Lamsa K, Smirnov S, Taira T, Voipio J (1997) Long-lasting GABAmediated depolarization evoked by high-frequency stimulation in pyramidal neurons of rat hippocampal slice is attributable to a network-driven, bicarbonate-dependent K+ transient. J Neurosci 17:7662-7672. Medline
Kaila K, Ruusuvuori E, Seja P, Voipio J, Puskarjov M (2014) GABA actions and ionic plasticity in epilepsy. Curr Opin Neurobiol 26:34-41. CrossRef Medline

Klaassen A, Glykys J, Maguire J, Labarca C, Mody I, Boulter J (2006) Seizures and enhanced cortical GABAergic inhibition in two mouse models of human autosomal dominant nocturnal frontal lobe epilepsy. Proc Natl Acad Sci U S A 103:19152-19157. CrossRef Medline

Menendez de la Prida L, Trevelyan AJ (2011) Cellular mechanisms of high frequency oscillations in epilepsy: on the diverse sources of pathological activities. Epilepsy Res 97:308-317. CrossRef Medline

Miles R, Wong RK (1983) Single neurones can initiate synchronized population discharge in the hippocampus. Nature 306:371-373. CrossRef Medline

Miles R, Tóth K, Gulyás AI, Hájos N, Freund TF (1996) Differences between somatic and dendritic inhibition in the hippocampus. Neuron 16:815823. CrossRef Medline

Netoff TI, Schiff SJ (2002) Decreased neuronal synchronization during experimental seizures. J Neurosci 22:7297-7307. Medline

Pallud J, Le Van Quyen M, Bielle F, Pellegrino C, Varlet P, Labussiere M, Cresto N, Dieme MJ, Baulac M, Duyckaerts C, Kourdougli N, Chazal G, Devaux B, Rivera C, Miles R, Capelle L, Huberfeld G (2014) Cortical GABAergic excitation contributes to epileptic activities around human glioma. Sci Transl Med 6:244ra289. CrossRef Medline

Pinto DJ, Patrick SL, Huang WC, Connors BW (2005) Initiation, propagation, and termination of epileptiform activity in rodent neocortex in vitro involve distinct mechanisms. J Neurosci 25:8131-8140. CrossRef Medline

Prince DA, Wilder BJ (1967) Control mechanisms in cortical epileptogenic foci. "Surround" inhibition. Arch Neurol 16:194-202. CrossRef Medline

Raimondo JV, Kay L, Ellender TJ, Akerman CJ (2012) Optogenetic silencing strategies differ in their effects on inhibitory synaptic transmission. Nat Neurosci 15:1102-1104. CrossRef Medline

Sanchez-Vives MV, McCormick DA (2000) Cellular and network mechanisms of rhythmic recurrent activity in neocortex. Nat Neurosci 3:10271034. CrossRef Medline

Schevon CA, Weiss SA, McKhann G Jr, Goodman RR, Yuste R, Emerson RG, Trevelyan AJ (2012) Evidence of an inhibitory restraint of seizure activity in humans. Nat Commun 3:1060. CrossRef Medline

Shu Y, Hasenstaub A, McCormick DA (2003) Turning on and off recurrent balanced cortical activity. Nature 423:288-293. CrossRef Medline

Sloviter RS (1987) Decreased hippocampal inhibition and a selective loss of interneurons in experimental epilepsy. Science 235:73-76. CrossRef Medline

Staba RJ, Wilson CL, Bragin A, Fried I, Engel J Jr (2002) Quantitative analysis of high-frequency oscillations $(80-500 \mathrm{~Hz})$ recorded in human epileptic hippocampus and entorhinal cortex. J Neurophysiol 88:1743-1752. Medline

Staley KJ, Soldo BL, Proctor WR (1995) Ionic mechanisms of neuronal excitation by inhibitory GABAA receptors. Science 269:977-981. CrossRef Medline

Thompson SM, Gähwiler BH (1989a) Activity-dependent disinhibition. I. Repetitive stimulation reduces IPSP driving force and conductance in the hippocampus in vitro. J Neurophysiol 61:501-511. Medline

Thompson SM, Gähwiler BH (1989b) Activity-dependent disinhibition. II. Effects of extracellular potassium, furosemide, and membrane potential on $\mathrm{ECl}-$ in hippocampal CA3 neurons. J Neurophysiol 61:512-523. Medline

Thompson SM, Gähwiler BH (1989c) Activity-dependent disinhibition. III. Desensitization and GABAB receptor-mediated presynaptic inhibition in the hippocampus in vitro. J Neurophysiol 61:524-533. Medline

Traub RD, Miles R (1991) Neuronal networks of the hippocampus. Cambridge, UK: Cambridge UP.

Traub RD, Jefferys JG, Whittington MA (1999) Fast oscillations in cortical circuits. Cambridge, MA: Massachusetts Institute of Technology.

Trevelyan AJ (2009) The direct relationship between inhibitory currents and local field potentials. J Neurosci 29:15299-15307. CrossRef Medline

Trevelyan AJ, Jack J (2002) Detailed passive cable models of layer 2/3 pyramidal cells in rat visual cortex at different temperatures. J Physiol 539: 623-636. CrossRef Medline

Trevelyan AJ, Sussillo D, Watson BO, Yuste R (2006) Modular propagation of epileptiform activity: evidence for an inhibitory veto in neocortex. J Neurosci 26:12447-12455. CrossRef Medline

Zhang F, Wang LP, Brauner M, Liewald JF, Kay K, Watzke N, Wood PG, Bamberg E, Nagel G, Gottschalk A, Deisseroth K (2007) Multimodal fast optical interrogation of neural circuitry. Nature 446:633-639. CrossRef Medline

Zsiros V, Maccaferri G (2008) Noradrenergic modulation of electrical coupling in GABAergic networks of the hippocampus. J Neurosci 28:18041815. CrossRef Medline 